\title{
High B test of a commercial step-down Point of Load for LHC experiments
}

\author{
Massimo Lazzaroni ${ }^{1,2, \S}$, Mauro Citterio ${ }^{2}$, Stefano Latorre $^{2}$, Agostino Lanza $^{3}$ \\ ${ }^{1}$ Dipartimento di Fisica - Università degli Studi di Milano, Via Celoria, 16 \\ 20133 Milano (MI), Italy \\ e-mail: massimo.lazzaroni@unimi.it \\ $\S$ Corresponding Author \\ ${ }^{2}$ INFN - Milano, Via Celoria, 16 \\ 20133 Milano (MI), Italy \\ ${ }^{3}$ INFN - Pavia, via A. Bassi, 6 \\ 27100 Pavia, Italy
}

\begin{abstract}
The performance in magnetic field (B-field) of the commercial DC-DC converter LTM8033, from Linear Technology, has been evaluated. The tests have been carried out at the Laboratorio Acceleratori e Superconduttività Applicata (LASA), in Milan (Italy), on December 2013 and the experimental results are here presented and discussed. Their ability to operate in hostile environment is particularly interesting for physics experiments where the presence of radiation and strong B field make electronic devices challenged to function . In particular, in this article the operation in high B-field environment will be investigated and discussed.
\end{abstract}

Index Terms - Point of Load, Measurement, Efficiency evaluation, LHC, High-B tolerance, Reliability, Dependability, Hostile environment. 


\section{Introduction}

The Large Hadron Collider (LHC) is, nowadays, the world's largest and highest-energy particle operative accelerator, built by the European Council for Nuclear Research (CERN). Founded in 1954, the CERN laboratory sits aside the Franco-Swiss border near Geneva [1]. The LHC can be used in order to verify the predictions of different theories of particle physics with particular attention to prove the existence of the Higgs boson [2], [3], but also the large family of new particles predicted by super-symmetric theories. The aforementioned collider extends the frontiers of particle physics thanks to its high energy and luminosity [4] - [16]. It is important to underline that inside the collider high interaction rates, radiation doses, particle multiplicities and energies are extremes. All these challenges push the features of the electronic instrumentation and measurement equipment at new standards, which must be taken in account during the design phase. This is particularly true for the ATLAS (A Toroidal LHC ApparatuS) experiment [1], [4]. In fact, electronic converters employed in power supplies in this and other LHC experiments operate in hostile environment, due to the simultaneous presence of radiation and high static B-field, which imposes severe design constraints. Moreover, power supplies has to be quasi-adiabatic, due to the proximity of very sensitive detectors, and this requirement implies water cooling and very stringent thermal constraints [5]. Thermal management represents the key issue in designing these converters, and accurate thermal modeling is mandatory to maximize the RAMS performance (Reliability, Availability, Maintainability and Safety) [6]. This aspects have been developed during a research program denoted as Apollo, funded by INFN - Italy as described in the cited literature. These aspects will not be further discussed in the following. However, it would be noted that a correct thermal management of semiconductor devices is very important in order to gain high values of reliability indexes. Temperature is in fact an influence factor that, at certain values, lead to shorter lifetime of such devices.

The Phase-2 upgrade of the LHC is planned in 2022 long shutdown (even if the schedule can change). Detectors will be upgraded or replaced, and the new ones will be installed to improve the performances and sustain the higher rates and background at the new design luminosity: $5 \times 10^{34} \mathrm{~cm}^{-2} \mathrm{~s}^{-1}$. The increase of radiation background will cause the accumulation of a Total Ionizing Dose (TID) up to $10 \mathrm{kGy}$ in Silicon, and fluences up to $2 \times 10^{13}$ protons $/ \mathrm{cm}^{2}$ and $8 \times 10^{13}$ neutrons $/ \mathrm{cm}^{2}$. Both the new scenario and the increased power demand of the detectors lead to a re-design of the power distribution system. 
Many tests are necessary in order to verify whether a device can be used in this scenario. In this paper the robustness against B-field of a commercial device is described.

The test has been performed at the LASA [8], which is a center for research and development in the fields of accelerators and superconductivity of the University of Milan and the Istituto Nazionale di Fisica Nucleare (INFN), devoted to the study and development of technologies for the design, the implementation and the test of particle accelerators. It also includes a radiochemical laboratory for the production of radionuclides for diagnostic and metabolic radiotherapy.

The LASA offered also a decisive contribution to the development and industrial production of several superconducting components for projects like superconducting magnets (dipoles from 8 Tesla 15 meters long LHC accelerator and the Barrel toroid magnet of Atlas), and the superconducting RF cavities and cryo-modules for many applications, such as new radiation sources (European XFEL). In addition, the LASA has boosted activities for the transmutation of nuclear waste and the production of photocathodes for electron sources of high intensity.

In section II a general introduction on Point of Load is given. Section III highlights the experimental setup used to test the commercial devices, whereas in Section IV experimental results will be shown. Section V is devoted to the discussion of the results. Finally in Section VI conclusion are drawn. 


\section{Points of Load for Physics experiments}

Points of Load (PoL) power supplies are devices that are able to solve the challenge of high peak currents demand with low noise [9]. These features are often required in modern electronic equipment, in particular in systems where high performance semiconductors are present. At this aim, the design strategy places the individual power supply regulators as close as possible to the point of use.

PoL have been used for many years in different applications. In more recent years the introduction of both powerful microcontrollers and microprocessors required the regulation of low level voltage with high current capability. The typical approach with a single centralized traditional AC-DC conversion is not able to answer to these new requirements. This is due to the presence of connection with high resistivity such as wires, printed circuit board strips and connectors. Thus, the first solution to these new requirements has been found in the architecture drawn in Figure 1.

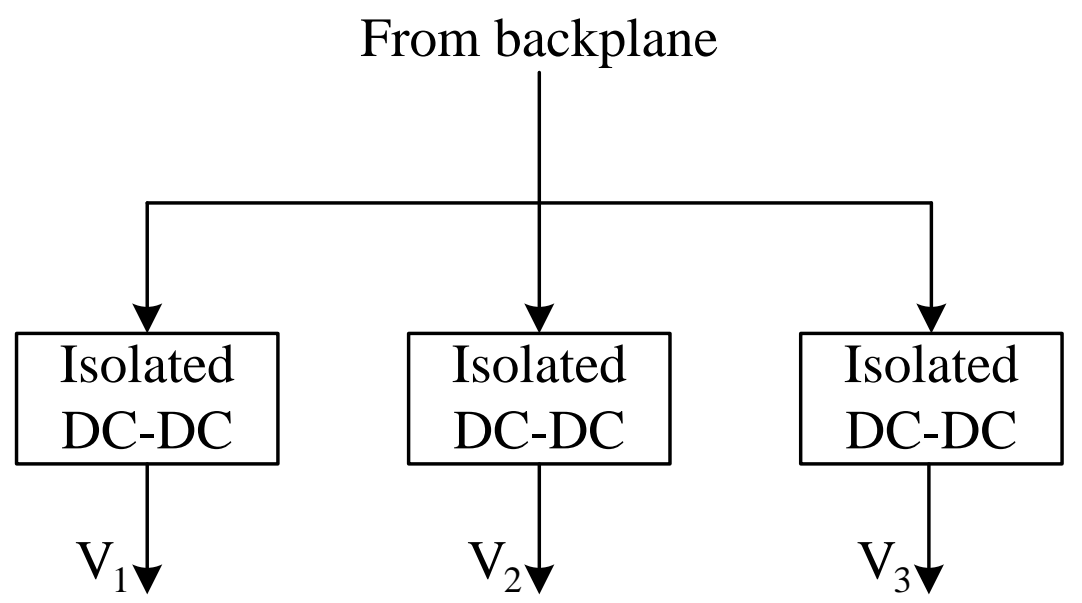

Figure 1 - Traditional distributed power architecture (voltage from backplane ranges from $24 \mathrm{~V}_{\mathrm{DC}}$ to $280 \mathrm{~V}_{\mathrm{DC}}$, the latter voltage value is used, for example, in the Liquid Argon (LAr) calorimeter of the ATLAS experiment at CERN).

As both the number of devices and the complexity of the systems increased, a new solution, based on the Intermediate Bus Architecture (IBA), has been proposed. The IBA architecture is depicted in Figure 2. 


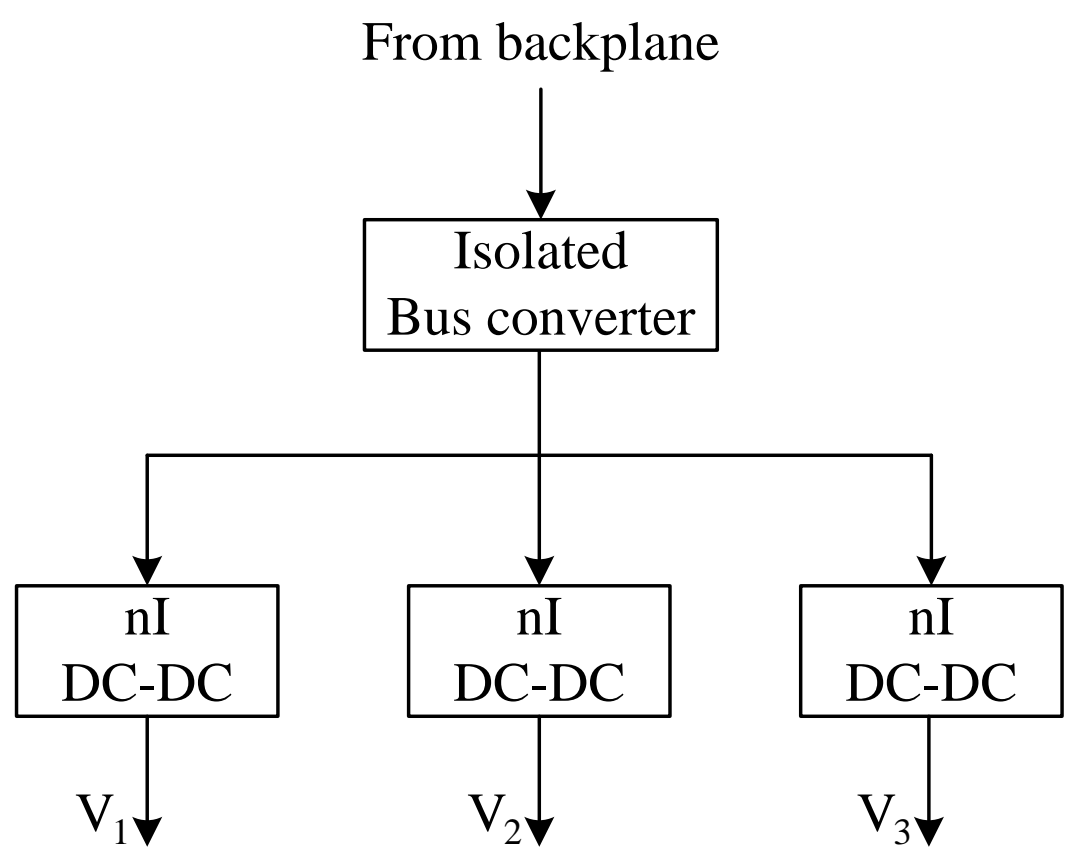

Figure 2 - Intermediate Bus Architecture.

For example, the present layout of the ATLAS LAr calorimeter consists of 58 main isolated DC-DC converters (Main Converters) with seven different outputs (ranging from $-7 \mathrm{~V}$ to +11 V) followed by many distributed low drop-out (LDO) regulators (see Figure 3) [10].

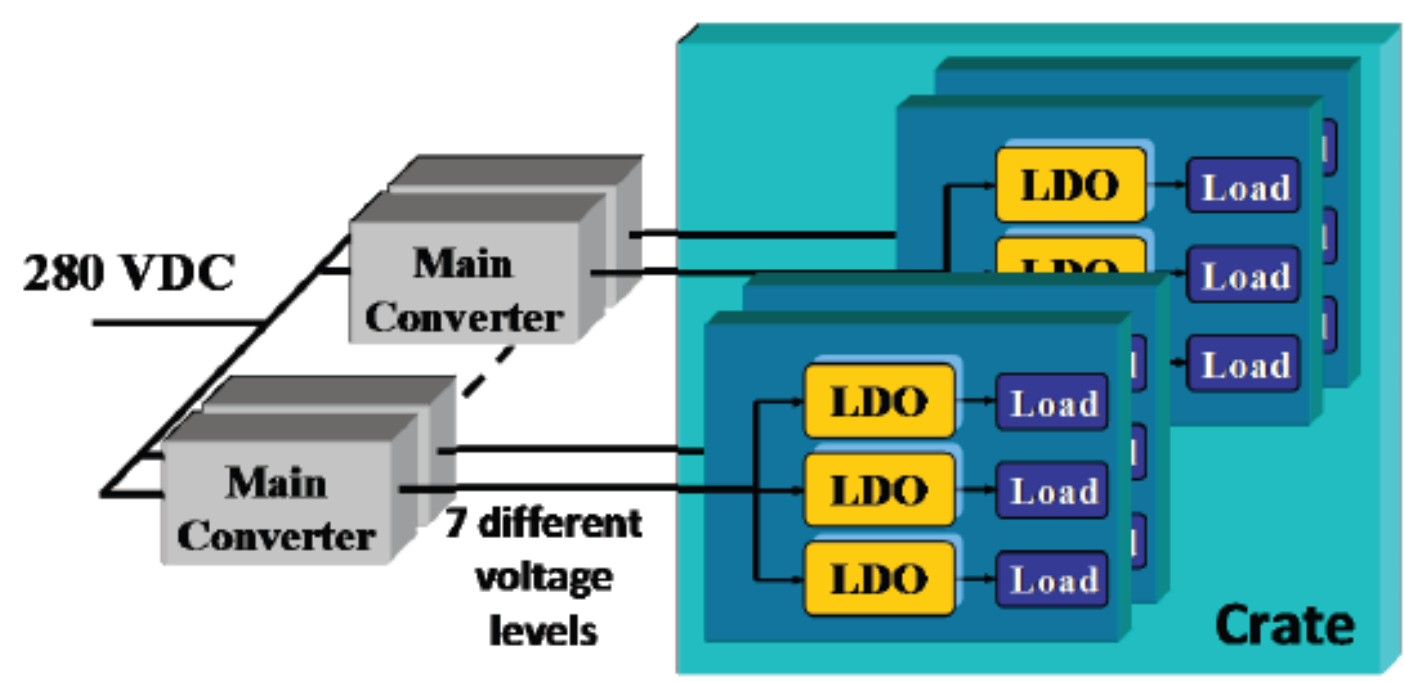

Figure 3 - Present implementation of the ATLAS LAr calorimeter power supplies [10].

Each main converter supplies up to 36 front-end boards in a custom crate installed very close to it, as shown in Figure 4. 


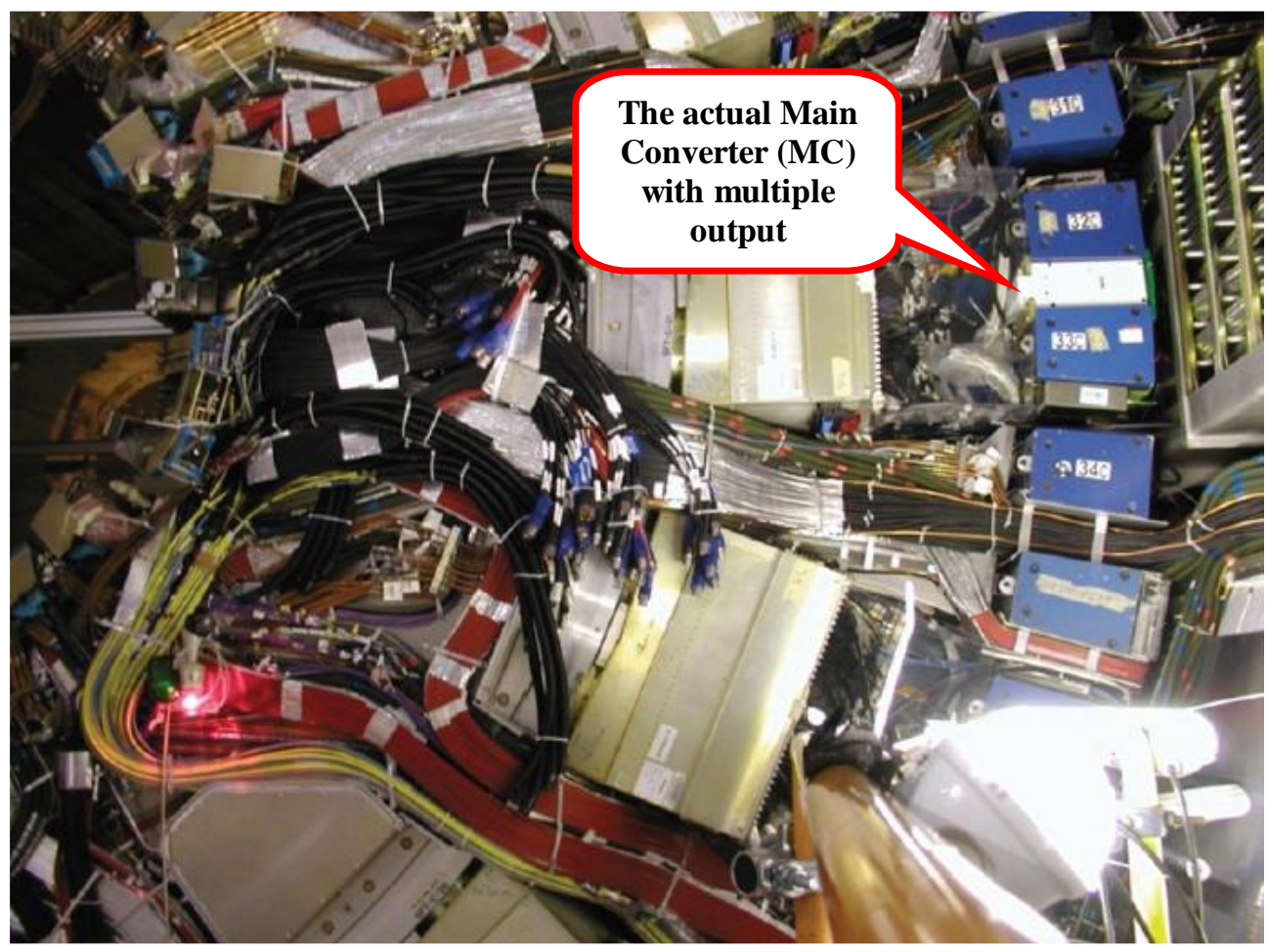

Figure 4 - Layout of the electronics and power supplies of the ATLAS LAr Barrel calorimeter.

Power connections are realized by means of huge cross-section cables, about 1 meter long, making the voltage drop on them negligible.

The use of LDO devices, as depicted in Figure 3, has the drawback of requiring specific input voltages to reduce as much as possible their power consumption, leading to a proliferation of the needed main converter outputs. For this reason we have considered a different system architecture, generating just one main converter output followed by many PoL converters with a high step-down ratio [11] - [24].

In the proposed architecture a single 12 VDC (suitable intermediate value) bus is considered, which is fed by an isolated DC-DC resonant converter with redundancy characteristic, the so called Main Converter (MC).

The proposed redundancy is based on the functional configuration $k$ out of $n$, represented by a system operative when at least $k$ number of elements out of a total of $n$ elements are functioning normally. The configuration is also called $k$-out-of-n redundancy with $k \leq n$. For this configuration we can assume a structure in which $k$ elements are in active redundancy and the remaining elements $(n-k)$ are in stand-by. A typical example is a steel cable formed of $n$ strands that can withstand the foreseen stress if at least $k$ numbers of strands are intact. ). In fact, in the proposed configuration three $1.5 \mathrm{~kW}$ Main Converter modules work together in order to deliver a total power of $3 \mathrm{~kW}$. The load is, in this way, shared and each module 
delivers $1 \mathrm{~kW}$ during safe operations. If a module fails the remaining two modules share the full load (in fact, each module is able to operate up to $1.5 \mathrm{~kW}$ ).

The DC bus is distributed to the electronic front-end and read-out boards, where non-isolated Point of Load (niPOL) converters are used to gain the necessary voltage level and regulation. This power distribution concept is illustrated in Figure 5.

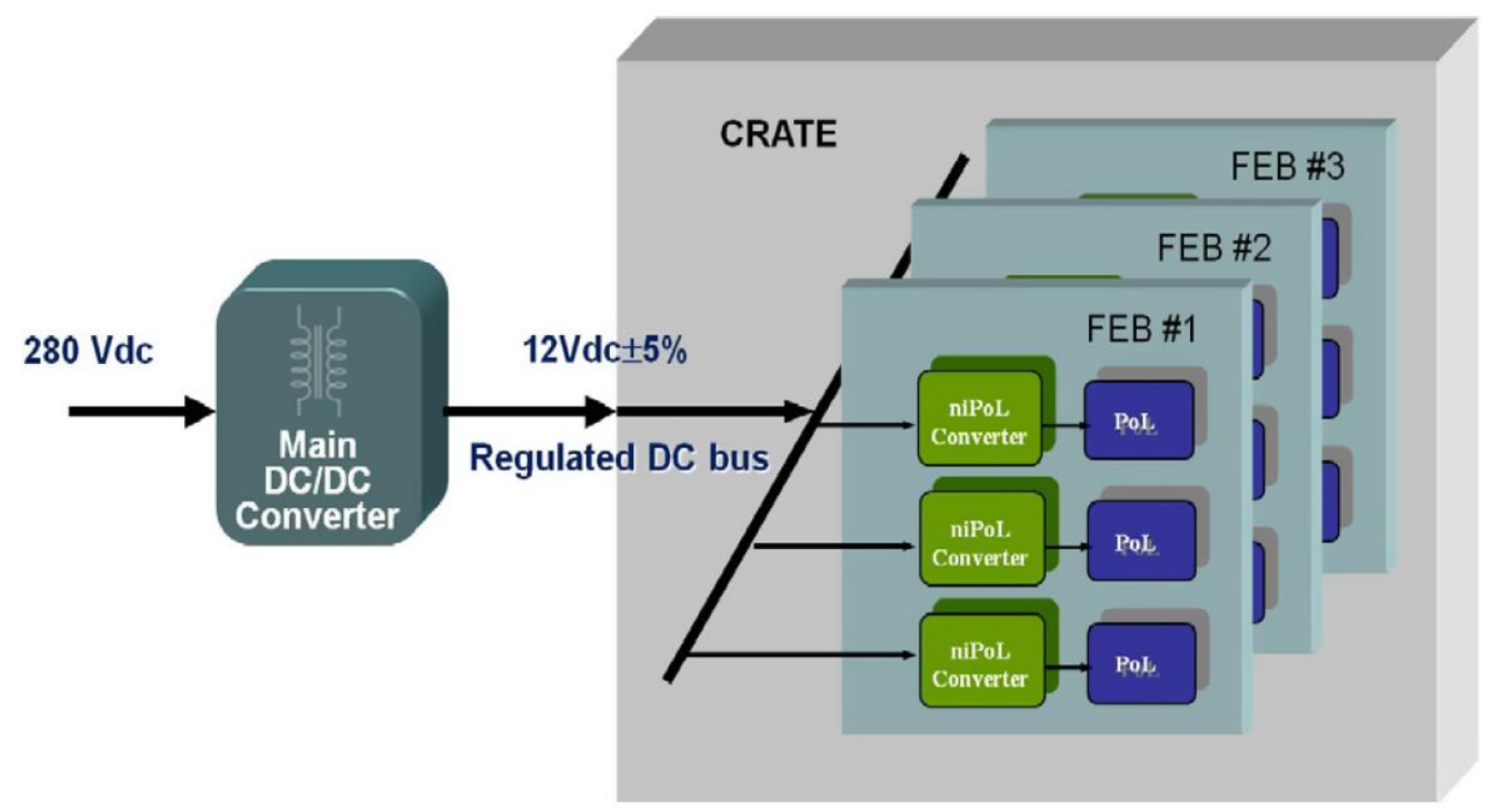

Figure 5 - Proposed power supply distribution system ( $n i \mathrm{POL}=$ non-isolated Point of Load).

It is important to emphasize that the choice of the 12 VDC bus voltage is just an example, other values could be selected as well. For example, a 48 VDC bus could be used to directly supply $n i \mathrm{POL}$ converters for load requiring few volts and another intermediate bus voltage (for example $12 \mathrm{VDC}$ ) could be generated locally to supply $n i \mathrm{POL}$ converters that need to provide very low output voltages (i.e. for voltages less than $2 \mathrm{~V}$ ).

\section{The device under test (DUT)}

In the present paper, a commercial niPoL, LTM8033 by Linear Technology, has been verified under high B-field conditions [25]. At this aim an evaluation board (DC1623A), shown in Figure 8, has been used.

The LTM8033 ${ }^{\circledR}$ is an EMI-compatible $36 \mathrm{~V}, 3 \mathrm{~A}$ DC/DC $\mu$ Module ${ }^{\circledR}$ buck converter. The device is designed in order to meet the radiated emissions requirements of the European EN55022 standard, but it should be noted that also conducted emission requirements can be met simply by adding a filter as declared by the manufacturer. A very interesting feature of 
this device is that all components such as the switching controller, the power switches, the inductor and the filters are included in a single package. In this way, the design phase is simple and the routing operation is easier. The input voltage ranges from $3.6 \mathrm{~V}$ to $36 \mathrm{~V}$, whereas the output voltage can be settled in a wide range: $0.8 \mathrm{~V}$ to $24 \mathrm{~V}$. Finally, the switching frequency, ranging from $200 \mathrm{kHz}$ to $2.4 \mathrm{MHz}$, can be set by selecting the value of a single resistor. Only the bulk input and output filter capacitors are needed in order to operate. The LTM $8033^{\circledR}$ is packaged in a thermally enhanced, compact over-molded land grid array (LGA) as depicted in Figure 6.

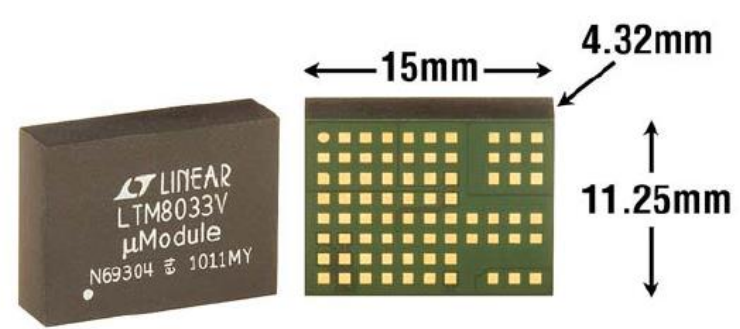

Figure 6 - The package photograph of the LTM8033 ${ }^{\circledR}$ device (not to scale) [25].

In order to test the device operating in the best configuration the evaluation board DC1623A, developed by Linear Technology, has been used [25], [26]. It features the LTM8033 ${ }^{\circledR}$, and it is pre-configured for a $3.3 \mathrm{~V}$ output from a $5.5 \mathrm{~V}$ to $36 \mathrm{~V}$ input [26].

The tests have been carried out on two evaluation boards, rotating their position in order to apply the B-field in different directions. The use of two different evaluation boards is useful to check the repeatability of the performance obtained in the planned condition by the devices (even if a test with only two devices cannot be used for statistic evaluation). 


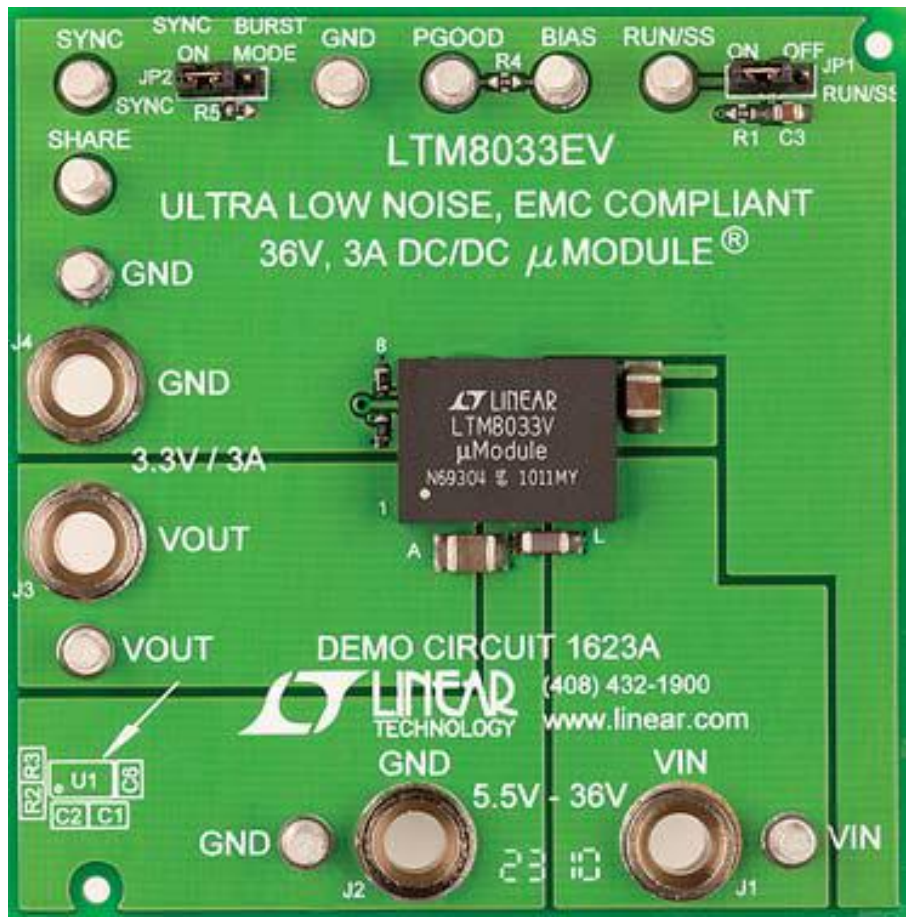

Figure 7 - The utilized evaluation board [26].

The schematic circuit of the evaluation board is reported in Figure 8.

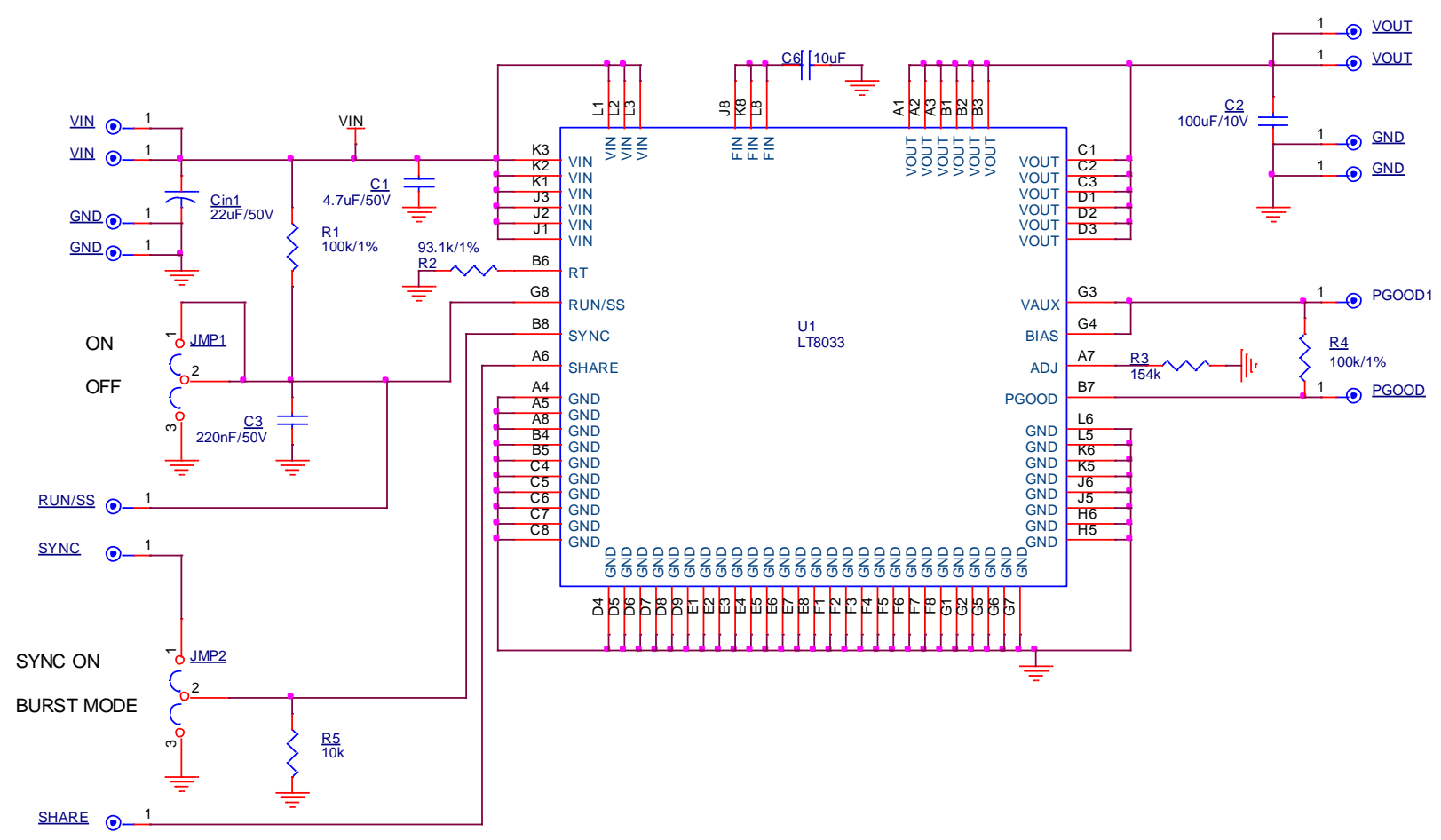

Figure 8 - The schematic circuit used for the test [26]. (The optional circuit of the Evaluation board is not used and it is not reported in figure [26]). 


\section{The experimental setup}

The experimental setup is depicted in Figure 9 together with the magnet used for B-Field generation. This system presents a characteristic curve shown in Figure 10, from which the maximum usable B-field is about $1.2 \mathrm{~T}$.

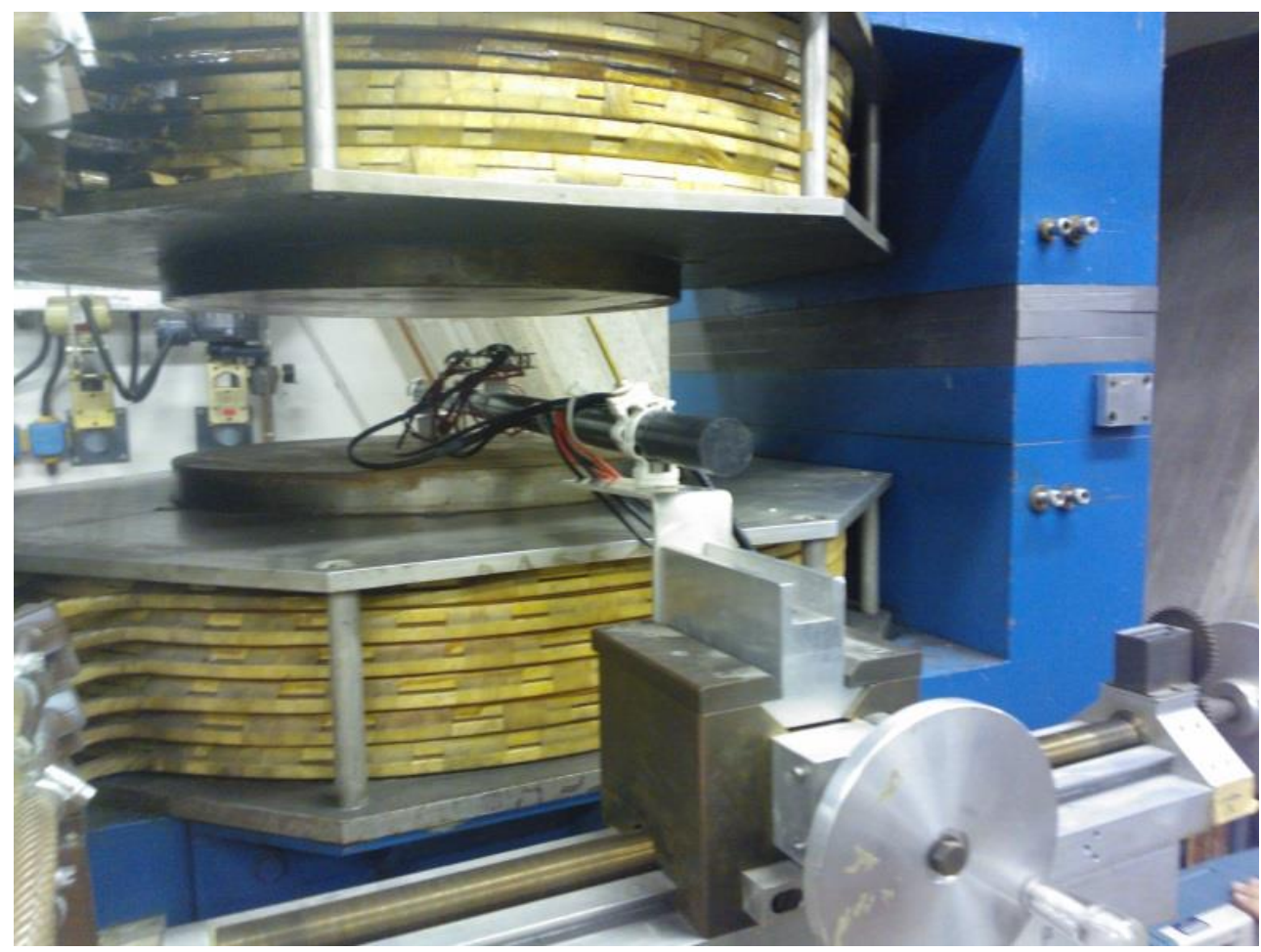

Figure 9 - The experimental setup.

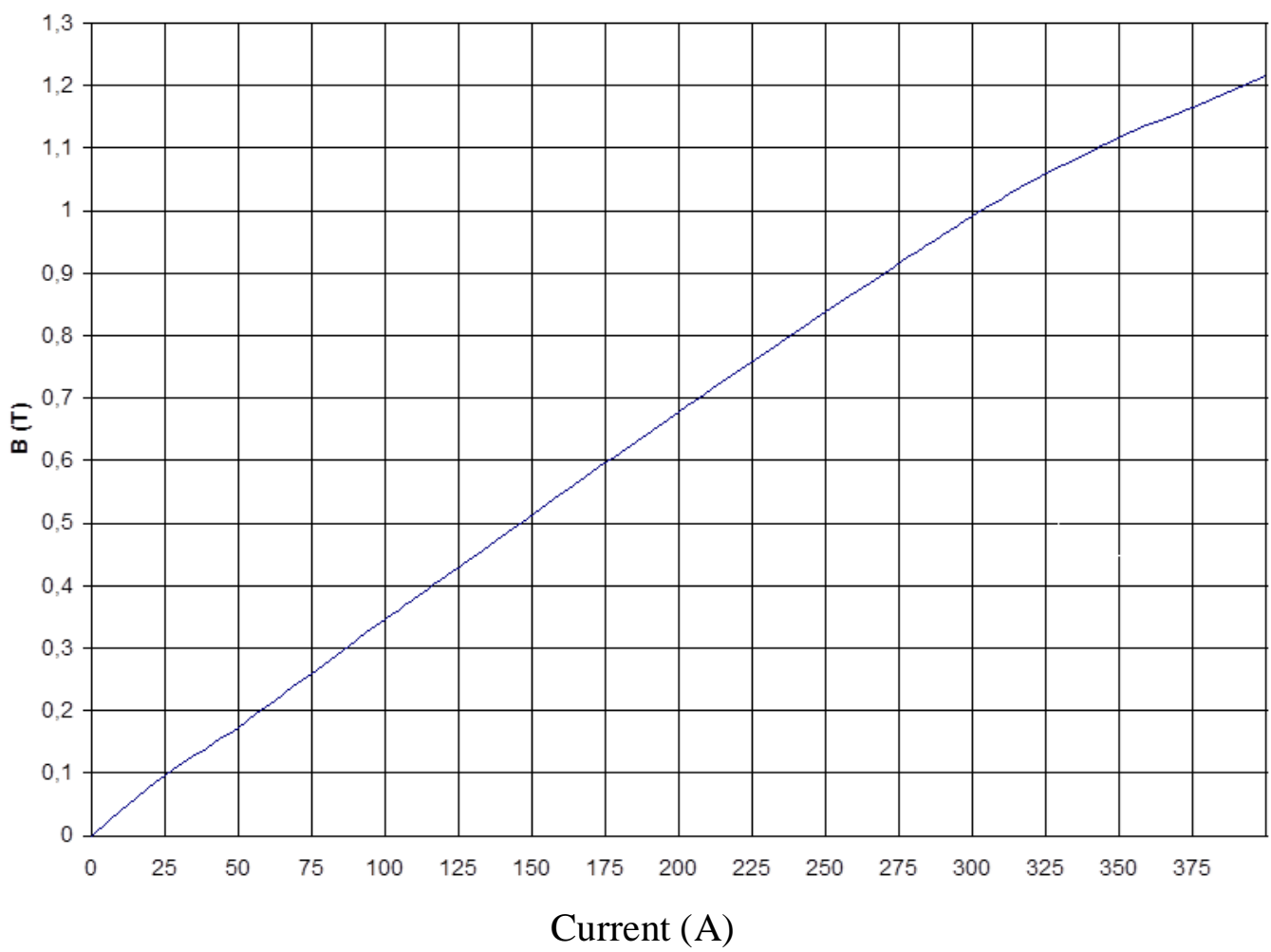

Figure 10 - B-field Vs Current of the utilized system. 
The system used is based on a solenoid devoted to setup the magnetic field. So, the applied current is about proportional to the induction obtained in the air gap where the boards are located during the test. The field value is, therefore, regulated by the current in the circuit according to the characteristic shown in Figure 10.

The used equipment consisted of a power supply, a 4-channel oscilloscope, a magnetic field measurement meter (DTM-133, by the Group3 company) and a multimeter for output voltage measurement.

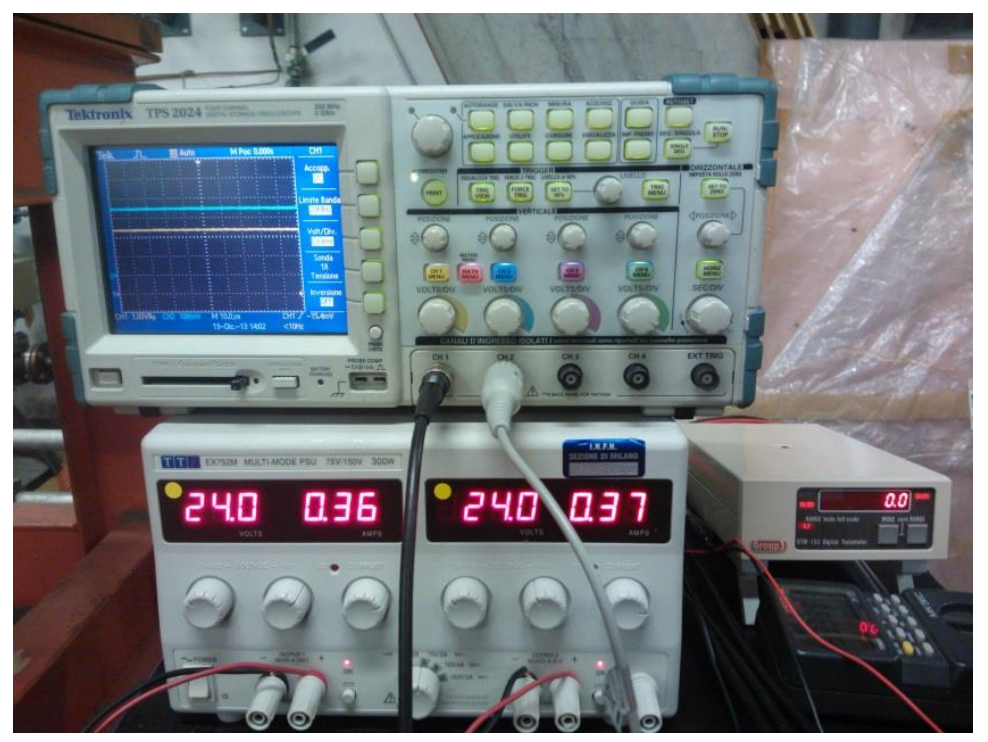

Figure 11 - The used measuring instruments.

Schematic of the simple test circuit is drawn in Figure 12.

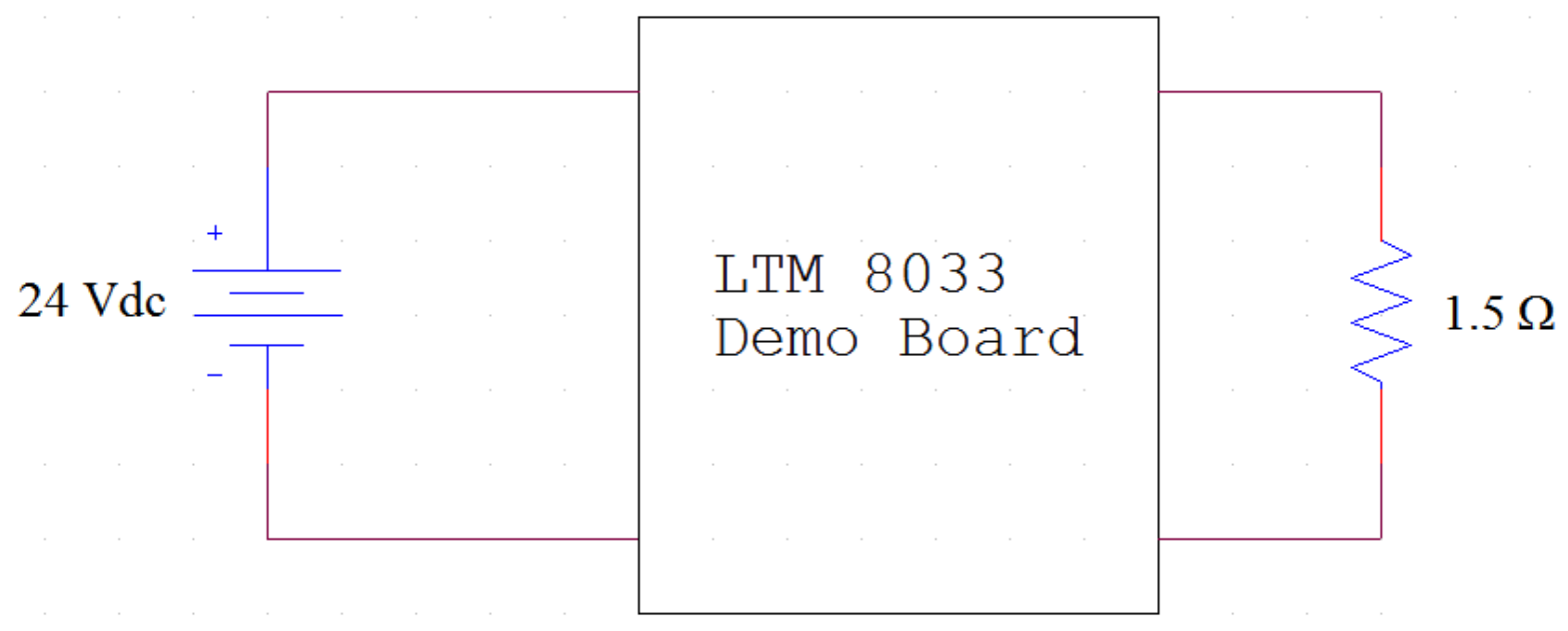

Figure 12 - The schematic circuit used during the test. 
The output voltage of the two used evaluation boards has been fixed by the manufacturer to $3.3 \mathrm{~V}$, in order to get the best performance, so we kept this default setting The input voltage of the evaluation board can vary from $3.6 \mathrm{~V}$ to $36 \mathrm{~V}$. This is a very large range and the device can be used in many situations. This is particularly true in industrial application, even if this topic is not further discussed in this paper.

The theory of operation of the tested device leads to consider that inside the input range fixed by the manufacturer its functionality is not particularly influenced by the input voltage. In the LHC experiments, higher is the input voltage and lower is the power consumption on cables connecting the primary AC/DC power supplies to the PoL, so its choice is mainly driven by the available AC/DC output voltages, which are $48 \mathrm{~V}$ and $24 \mathrm{~V}$

The operational conditions used for the test are reported in the following tables.

Table I

\begin{tabular}{c|c|c|c}
\hline Channel & Signal & Connector & Id \\
\hline CH1 & Input & E1 -E3 & VIN \\
\hline CH2 & Output & E2 - E4 & Vout \\
\hline \hline
\end{tabular}

Table II

\begin{tabular}{l|l|l}
\hline Parameter & \multicolumn{1}{|c}{ Description } & \multicolumn{1}{c}{ Value } \\
\hline \hline Vin & Input Voltage & $24 \mathrm{~V}$ \\
\hline Vout & Output Voltage & $3.3 \mathrm{~V}$ \\
\hline Load & Ohmic Load & $1.5 \Omega$ \\
\hline Iout & Output Current & $2.2 \mathrm{~A}$ \\
\hline Pout & Nominal Power & $7.26 \mathrm{~W}$ \\
\hline
\end{tabular}

The values of the input and output signals are reported in Table II. Input voltage is given by the experimental setup. Output voltage is, instead, fixed by the manufacturer of the evaluation board. Load is obtained by armored power resistors, and the value is the nominal one. The output current reported in Table II is evaluated using the nominal value:

$$
I_{\text {out }}=\frac{V_{\text {out }}}{R_{\text {load }}}=\frac{3.3}{1.5}=2.2 \mathrm{~A}
$$

Finally, power is obtained once again starting by the nominal values:

$$
P_{\text {out }}=V_{\text {out }} \times I_{\text {out }}=3.3 \times 2.2=7.26 \mathrm{~W}
$$


The tests have been carried out with the applied B-field in three directions. The instrumentation was turned on for a time sufficient to ensure the absence of thermal drifts before starting the test [27]. Before starting the measurements, the zero adjustment of the magnetic field meter (defined as the adjustment of a measuring system so that it provides a null indication corresponding to a zero value of a quantity to be measured, VIM, ISO/IEC Guide 99:2007-12 and corrigendum) [27] was performed. 


\section{Experimental results}

In this Section the experimental test are reported. Three directions have been used:

- Perpendicular, described in Section IV.a;

- Horizontal from right, described in Section IV.b;

- Horizontal from above, described in Section IV.c.

\section{a) B-field perpendicular}

B-field was applied to the evaluation boards as depicted in Figure 13. A part of the experimental set-up is visible in Figure 14.
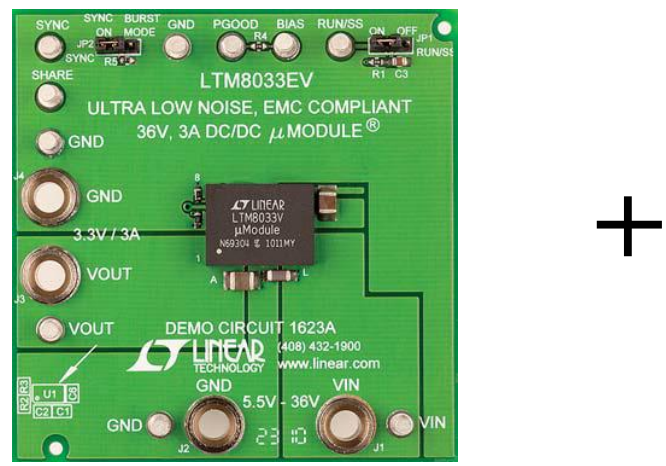

Figure 13 - B-field perpendicular to the plane of the sheet (entering).

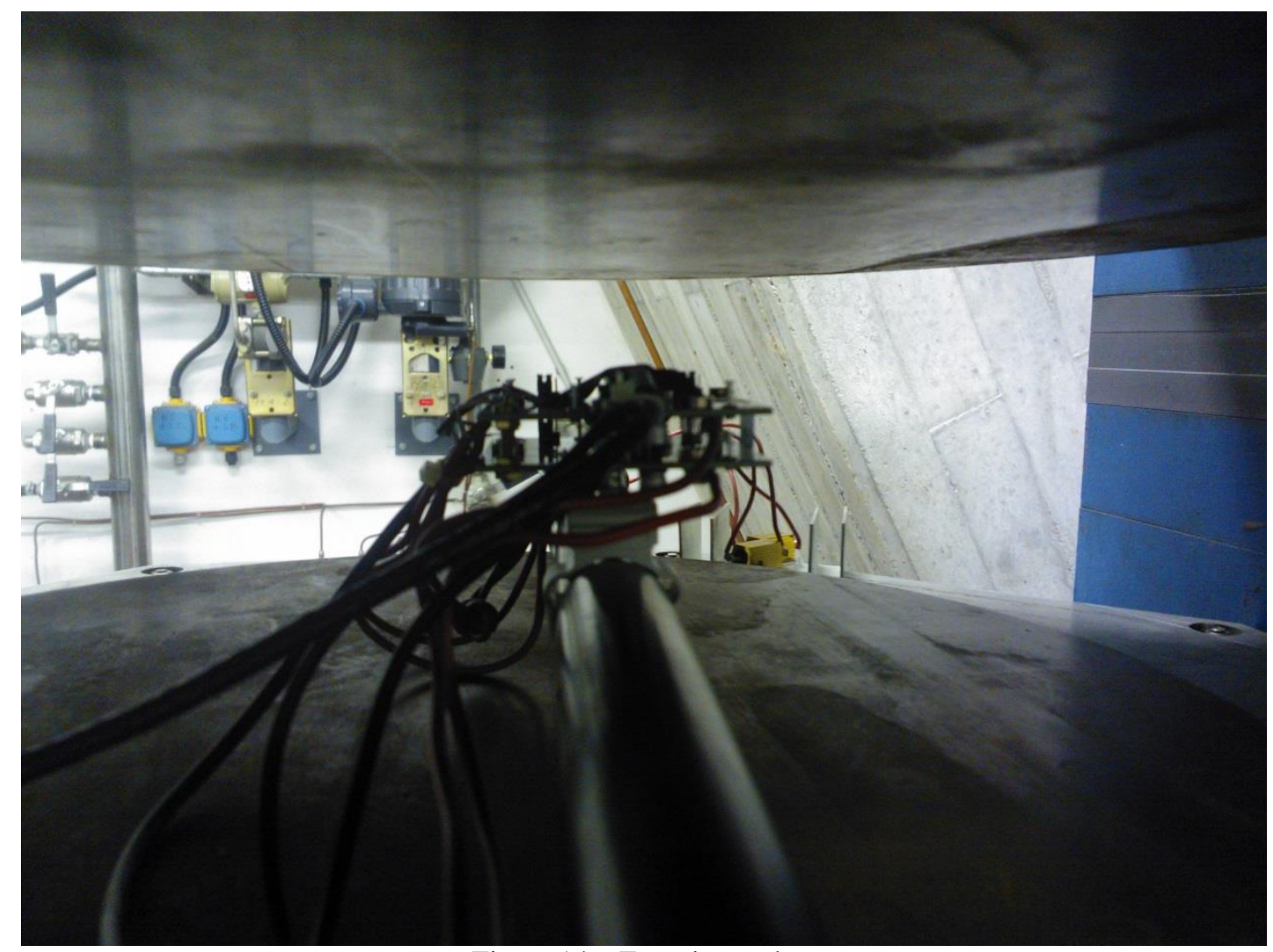

Figure 14 - Experimental set-up. 
Results of the experimental measurements are reported in the following Table III (for sake of simplicity only output voltage and efficiency are reported; current and ripple are not shown in the following tables. Measured current is, however, drawn in the following plots).

Table III - Results for B-field perpendicular.

\begin{tabular}{|c|c|c|c|c|c|}
\hline \multirow[b]{2}{*}{ Id } & \multirow{2}{*}{$\begin{array}{l}\text { Magnetic Field } \\
\text { (Gauss) }\end{array}$} & \multicolumn{2}{|c|}{ Evaluation board 1 (upper) } & \multicolumn{2}{|c|}{ Evaluation board 2 (lower) } \\
\hline & & $\begin{array}{l}\text { Vout } \\
(\mathrm{V})\end{array}$ & $\begin{array}{c}\text { Efficency } \\
(0-1)\end{array}$ & $\begin{array}{l}\begin{array}{l}\text { Vout } \\
\text { (V) }\end{array}\end{array}$ & $\begin{array}{c}\text { Efficency } \\
(0-1)\end{array}$ \\
\hline 1 & 0 & 3.332 & 0.857 & 3.338 & 0.837 \\
\hline 2 & 845 & 3.332 & 0.857 & 3.338 & 0.837 \\
\hline 3 & 1700 & 3.332 & 0.857 & 3.338 & 0.837 \\
\hline 4 & 2560 & 3.332 & 0.857 & 3.338 & 0.837 \\
\hline 5 & 3473 & 3.332 & 0.834 & 3.338 & 0.814 \\
\hline 6 & 4345 & 3.332 & 0.834 & 3.338 & 0.814 \\
\hline 7 & 4696 & 3.332 & 0.834 & 3.338 & 0.814 \\
\hline 8 & 5218 & 3.332 & 0.812 & 3.338 & 0.794 \\
\hline 9 & 6090 & 3.331 & 0.790 & 3.338 & 0.774 \\
\hline 10 & 6886 & 3.331 & 0.752 & 3.338 & 0.737 \\
\hline 11 & 7738 & 3.331 & 0.734 & 3.338 & 0.720 \\
\hline 12 & 8570 & 3.332 & 0.717 & 3.338 & 0.703 \\
\hline 13 & 9350 & 3.330 & 0.700 & 3.337 & 0.687 \\
\hline 14 & 10070 & 3.330 & 0.700 & 3.337 & 0.687 \\
\hline 15 & 6908 & 3.331 & 0.734 & 3.338 & 0.737 \\
\hline 16 & 3446 & 3.332 & 0.834 & 3.339 & 0.837 \\
\hline 17 & 862 & 3.332 & 0.857 & 3.339 & 0.837 \\
\hline 18 & 10 & 3.332 & 0.857 & 3.339 & 0.837 \\
\hline
\end{tabular}

Two different indexes have been considered as interesting for this type of test: the input current and the efficiency. These two indexes are drawn in Figure 15 and in Figure 16 respectively.

The input current tends to increase with the magnetic field. Similarly, the efficiency of the device tends to decrease, of less than $18 \%$ in the worst case, with the increase of the B-field. Finally, the device is able to operate in all the tested conditions. 


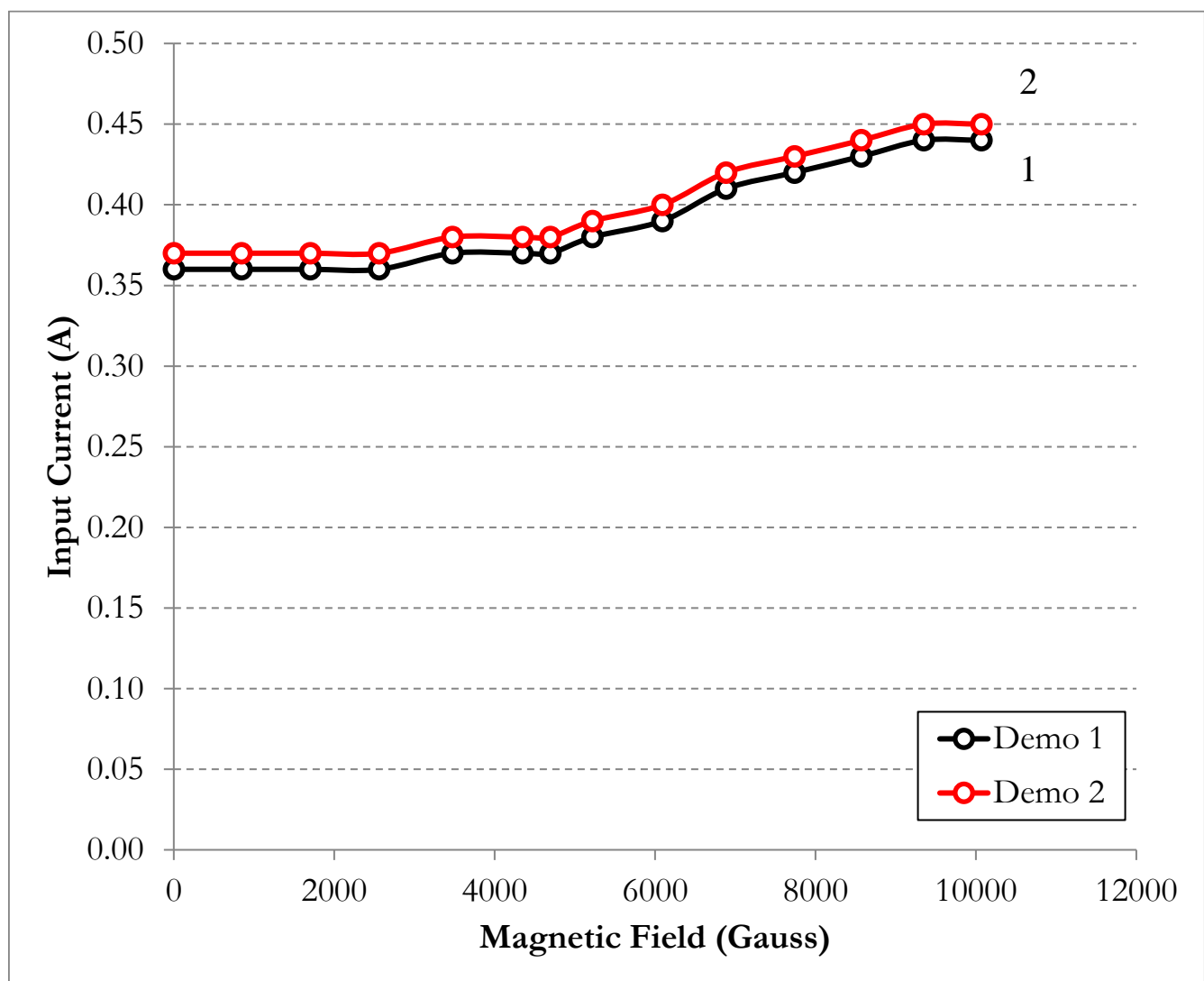

Figure 15 - Input Current (A) (Only the dashed part of the table is reported)

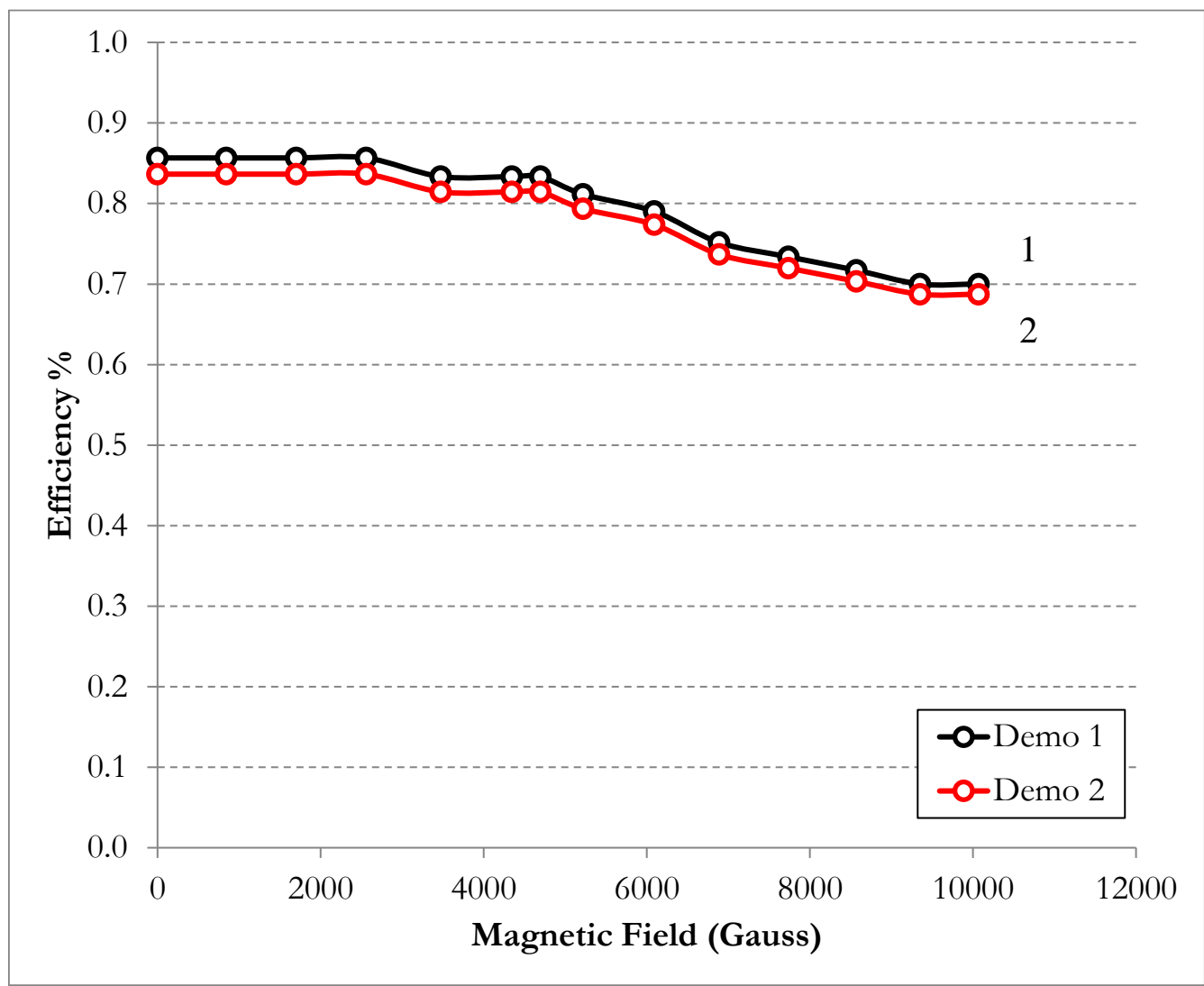

Figure 16 - Efficiency (Only the dashed part of the table is reported). 


\section{b) B-field horizontal from right}

B-field is applied to the evaluation board as depicted in Figure 17, and the setup is shown in Figure 18.

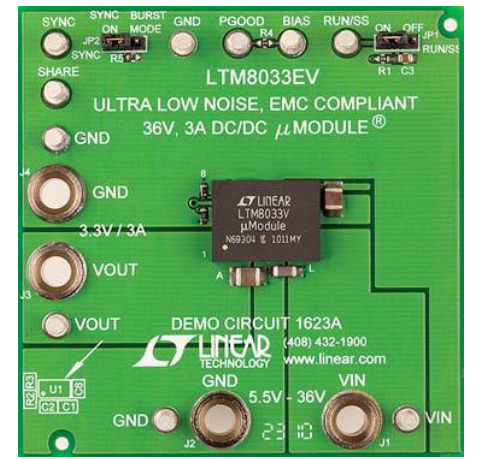

Figure 17 - B-field parallel to the plane of the sheet from right (where V02 is placed).

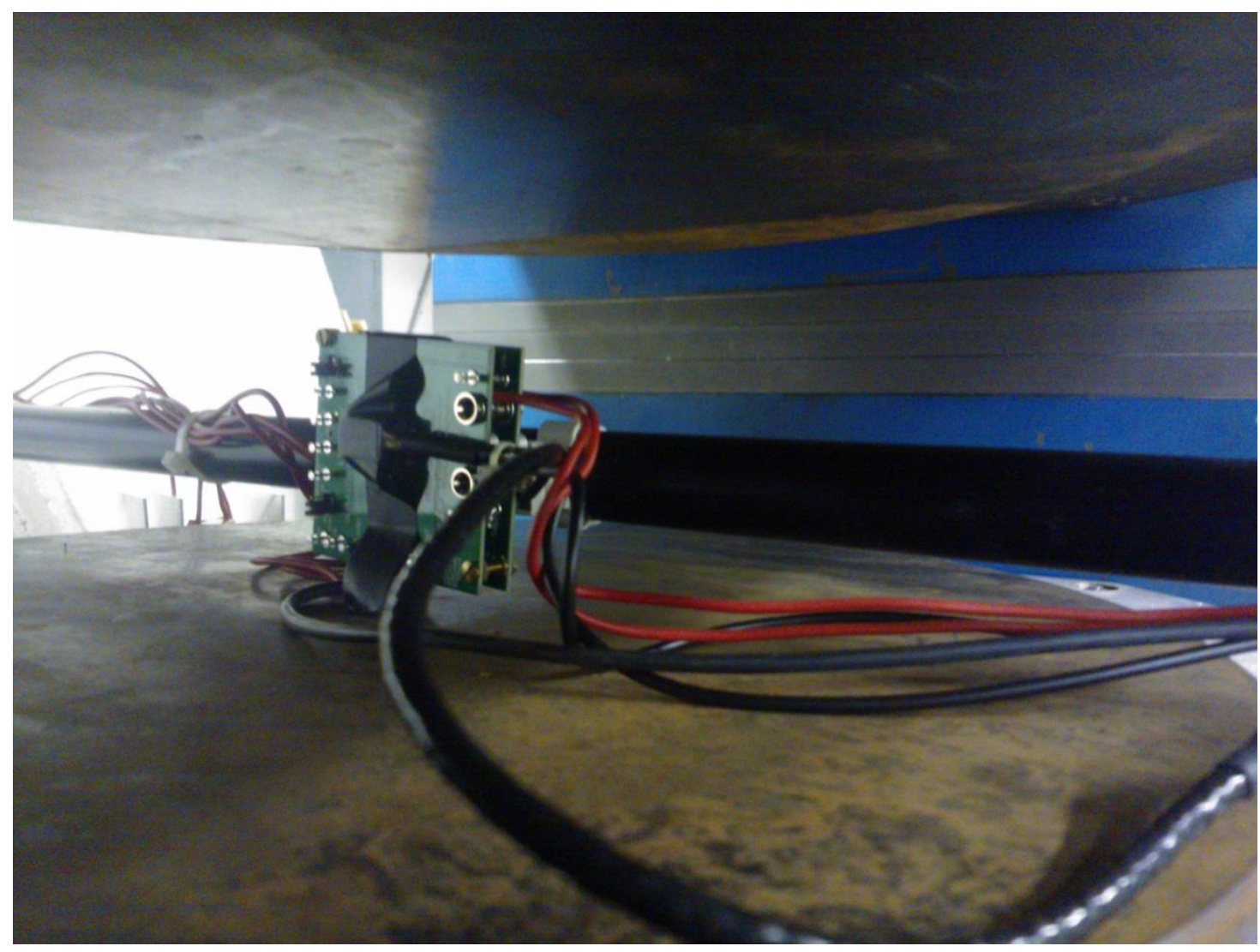

Figure 18 - Experimental Setup.

Results of the experimental measurements for this direction of field are reported in the following Table IV (even in this sub-section only output voltage and efficiency are reported; current and ripple are not shown in the following tables. However, measured current is has been plotted). 
Table IV - Results for B-field horizontal from the right.

\begin{tabular}{|c|c|c|c|c|c|}
\hline \multirow[b]{2}{*}{ Id } & \multirow{2}{*}{$\begin{array}{l}\text { Magnetic Field } \\
\text { (Gauss) }\end{array}$} & \multicolumn{2}{|c|}{ Evaluation board 1 (upper) } & \multicolumn{2}{|c|}{ Evaluation board 2 (lower } \\
\hline & & $\begin{array}{l}\text { Vout } \\
\text { (V) }\end{array}$ & $\begin{array}{c}\text { Efficency } \\
(0-1) \\
\end{array}$ & $\begin{array}{l}\text { Vout } \\
\text { (V) }\end{array}$ & $\begin{array}{c}\text { Efficency } \\
(0-1) \\
\end{array}$ \\
\hline 1 & 10 & 3.330 & 0.856 & 3.337 & 0.859 \\
\hline 2 & 800 & 3.330 & 0.856 & 3.337 & 0.859 \\
\hline 3 & 1606 & 3.331 & 0.856 & 3.337 & 0.859 \\
\hline 4 & 2420 & 3.331 & 0.856 & 3.337 & 0.836 \\
\hline 5 & 3232 & 3.330 & 0.833 & 3.337 & 0.836 \\
\hline 6 & 4058 & 3.331 & 0.811 & 3.337 & 0.814 \\
\hline 7 & 4384 & 3.331 & 0.811 & 3.337 & 0.793 \\
\hline 8 & 4876 & 3.331 & 0.790 & 3.337 & 0.793 \\
\hline 9 & 5696 & 3.331 & 0.790 & 3.337 & 0.773 \\
\hline 10 & 6514 & 3.331 & 0.771 & 3.337 & 0.773 \\
\hline 11 & 7328 & 3.331 & 0.752 & 3.337 & 0.754 \\
\hline 12 & 8118 & 3.331 & 0.752 & 3.337 & 0.754 \\
\hline 13 & 8860 & 3.331 & 0.752 & 3.337 & 0.736 \\
\hline 14 & 9546 & 3.331 & 0.734 & 3.337 & 0.736 \\
\hline 15 & 6524 & 3.331 & 0.771 & 3.338 & 0.755 \\
\hline 16 & 3232 & 3.331 & 0.833 & 3.338 & 0.814 \\
\hline 17 & 10 & 3.332 & 0.857 & 3.338 & 0.860 \\
\hline
\end{tabular}

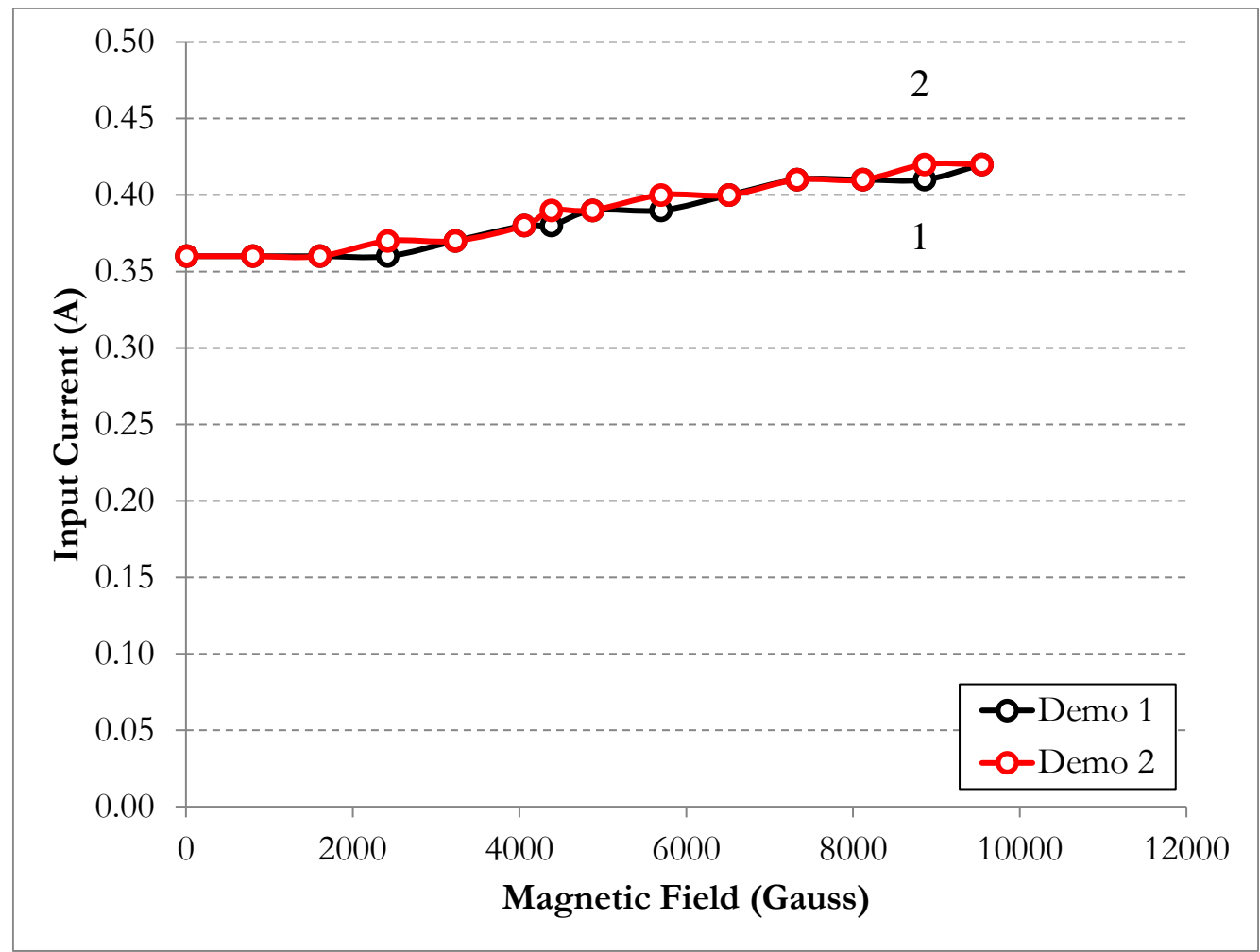

Figure 19 - Input Current (A) (Only the dashed part of the table is reported) 


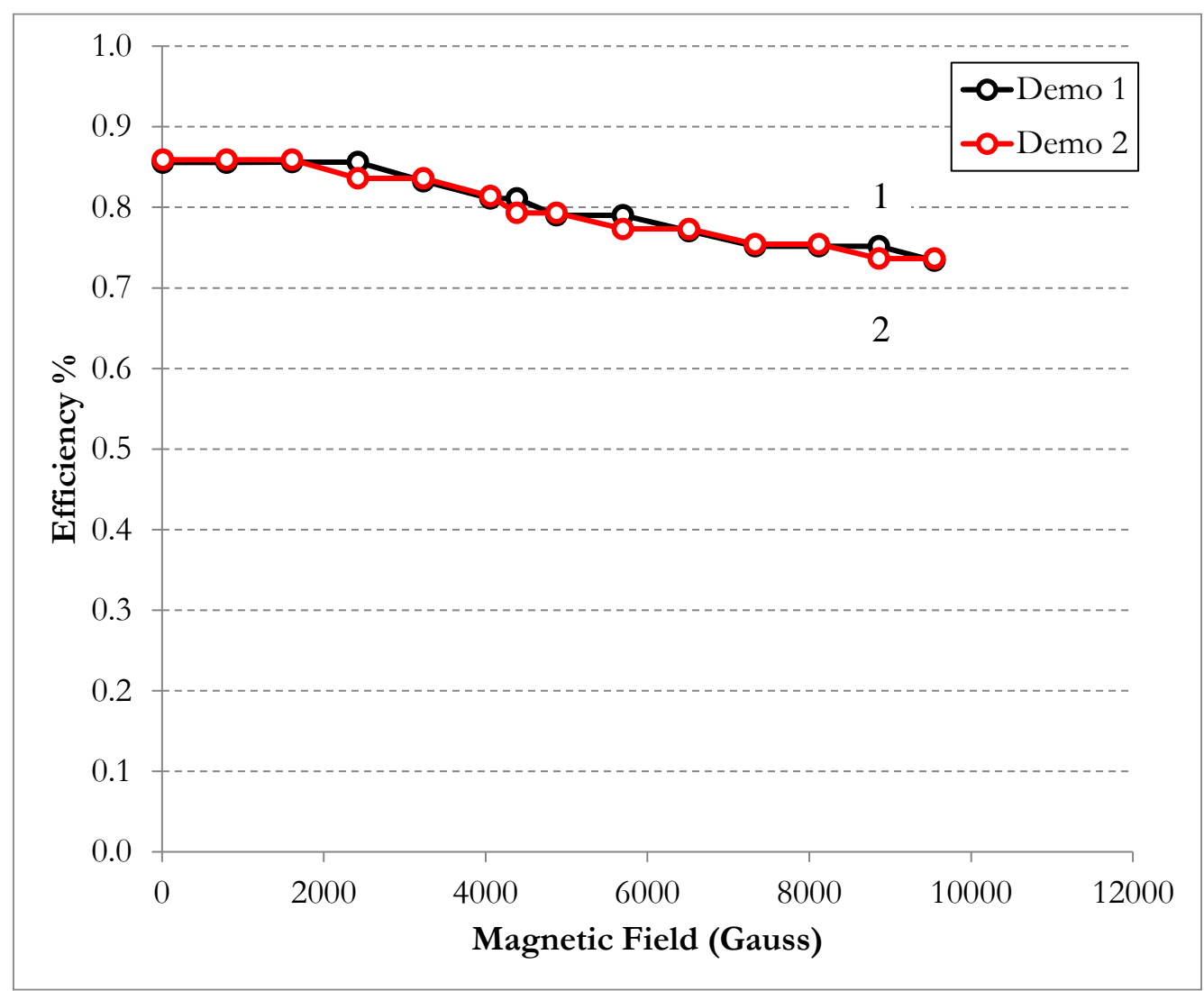

Figure 20 - Efficiency (Only the dashed part of the table is reported)

The input current tends to increase with the magnetic field. Similarly, the efficiency of the device tends to decrease, of about $14 \%$ in the worst case, with the increase of the magnetic field. The device is able to operate in all the tested conditions. 


\section{c) Horizontal B-field, from above}

B-field is applied to the evaluation board as depicted in Figure 21, and the setup is shown in Figure 22.

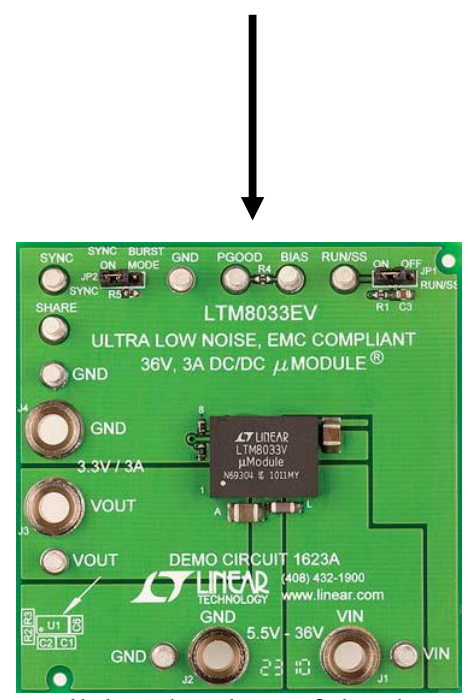

Figure 21 - B-field parallel to the plane of the sheet and entering from above.

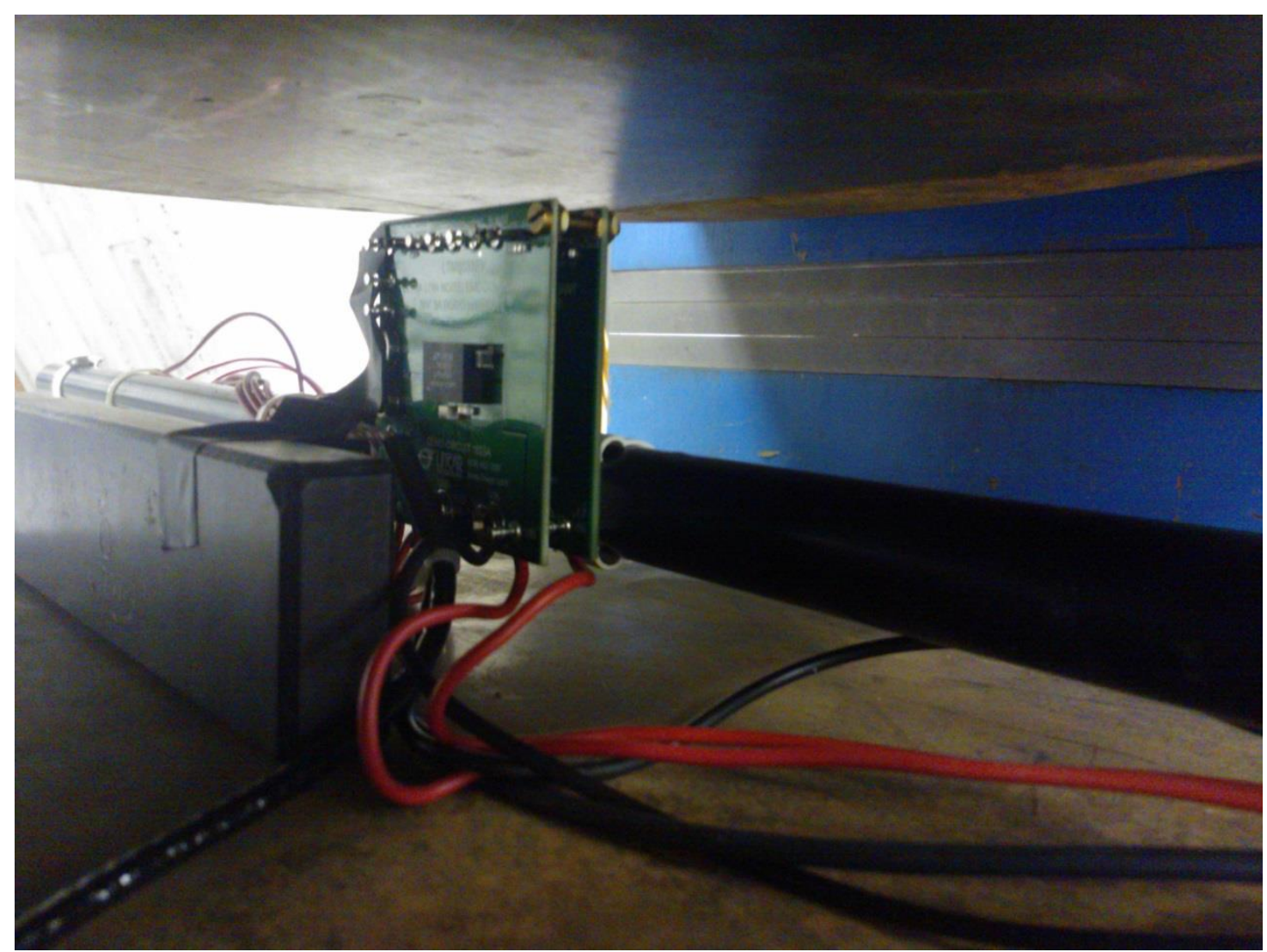

Figure 22 - Experimental Setup.

Results of the experimental measurements for this direction of field are reported in Table $\mathrm{V}$ (again, only output voltage and efficiency are reported; current and ripple are not shown in the following tables. However, measured current has been plotted). 
Table V - Results for B-field horizontal from above.

\begin{tabular}{|c|c|c|c|c|c|}
\hline \multirow[b]{2}{*}{ Id } & \multirow{2}{*}{$\begin{array}{l}\text { Magnetic Field } \\
\text { (Gauss) }\end{array}$} & \multicolumn{2}{|c|}{ Evaluation board 1 (upper) } & \multicolumn{2}{|c|}{ Evaluation board 2 (lower) } \\
\hline & & $\begin{array}{l}\text { Vout } \\
(\mathrm{V})\end{array}$ & $\begin{array}{c}\text { Efficency } \\
(0-1)\end{array}$ & $\begin{array}{l}\text { Vout } \\
\text { (V) }\end{array}$ & $\begin{array}{c}\text { Efficency } \\
(0-1)\end{array}$ \\
\hline 1 & 4 & 3.331 & 0.856 & 3.337 & 0.859 \\
\hline 2 & 784 & 3.331 & 0.856 & 3.337 & 0.859 \\
\hline 3 & 1556 & 3.331 & 0.856 & 3.337 & 0.859 \\
\hline 4 & 2326 & 3.331 & 0.833 & 3.337 & 0.836 \\
\hline 5 & 3104 & 3.331 & 0.811 & 3.337 & 0.814 \\
\hline 6 & 3884 & 3.331 & 0.790 & 3.337 & 0.793 \\
\hline 7 & 4660 & 3.331 & 0.790 & 3.337 & 0.773 \\
\hline 8 & 5434 & 3.331 & 0.771 & 3.337 & 0.773 \\
\hline 9 & 6204 & 3.331 & 0.752 & 3.338 & 0.755 \\
\hline 10 & 6970 & 3.331 & 0.752 & 3.338 & 0.755 \\
\hline 11 & 7714 & 3.332 & 0.734 & 3.338 & 0.737 \\
\hline 12 & 8416 & 3.332 & 0.734 & 3.337 & 0.736 \\
\hline 13 & 9062 & 3.332 & 0.734 & 3.337 & 0.719 \\
\hline 14 & 6208 & 3.331 & 0.752 & 3.338 & 0.755 \\
\hline 15 & 3092 & 3.331 & 0.811 & 3.337 & 0.814 \\
\hline 16 & 10 & 3.332 & 0.857 & 3.338 & 0.860 \\
\hline
\end{tabular}

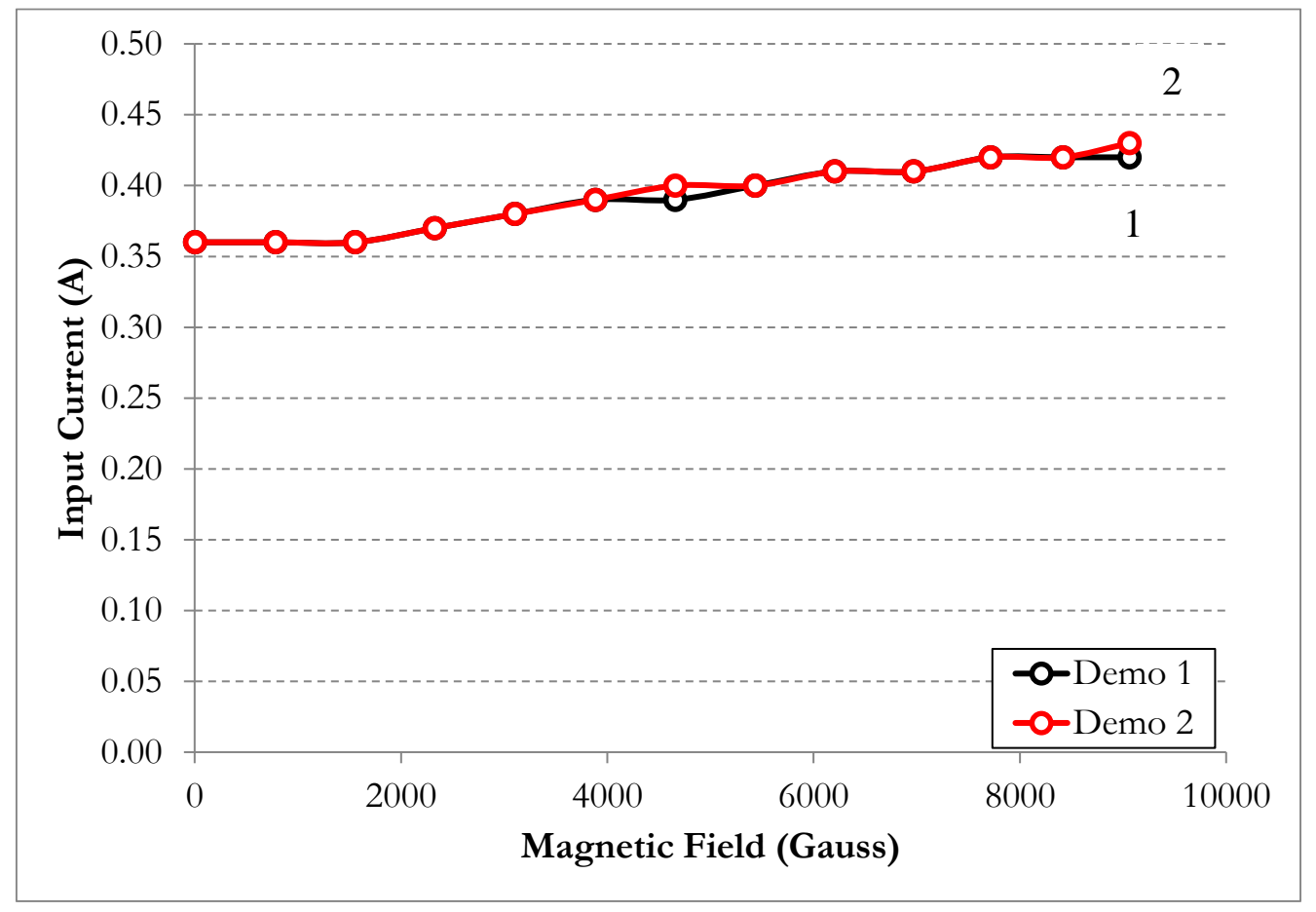

Figure 23 - Input Current (A) 


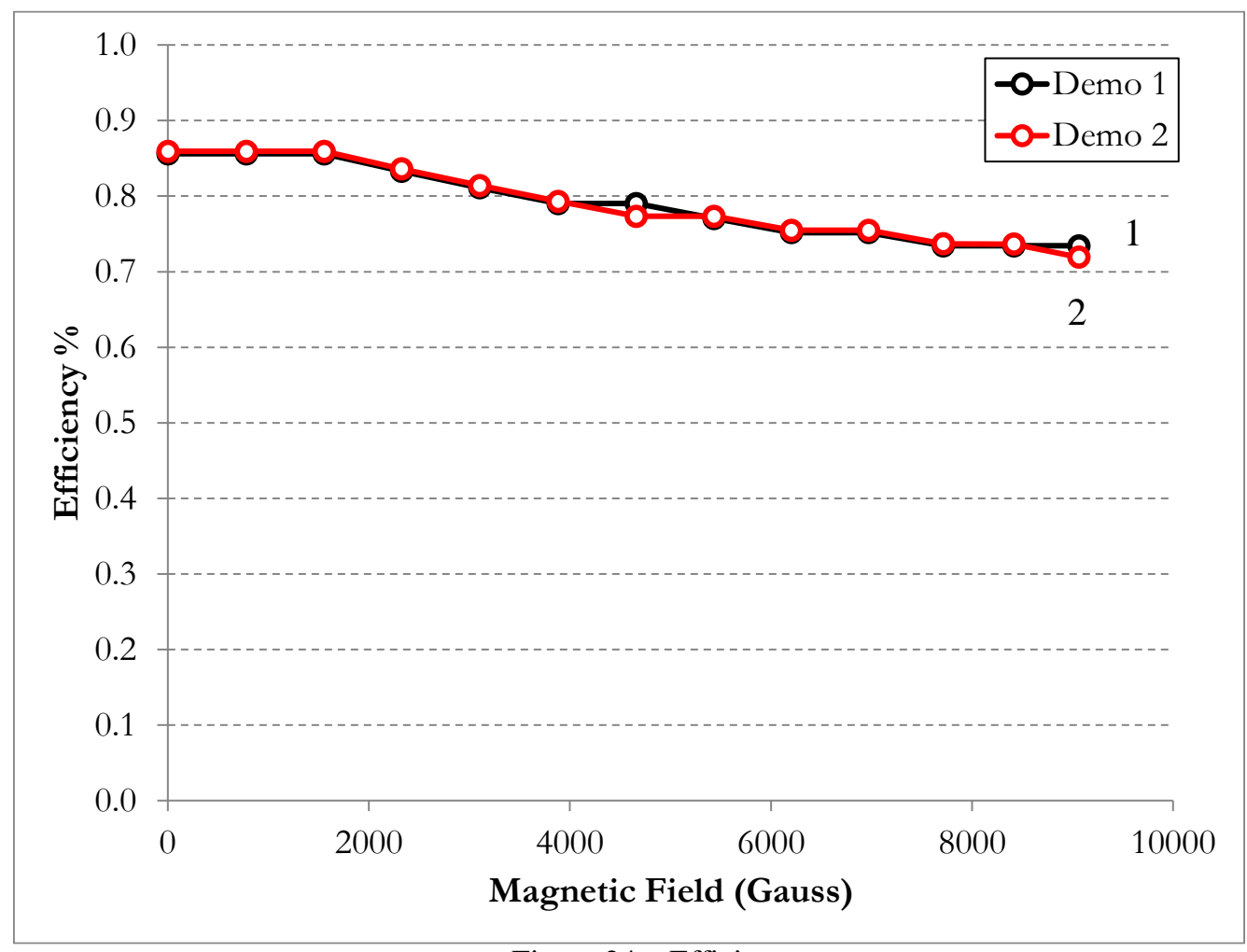

Figure 24 - Efficiency

The input current tends to increase with the magnetic field. Similarly, the efficiency of the device tends to decrease, of about $16 \%$ in the worst case, with the increase of the magnetic field. Again, the device is able to operate in all the tested conditions.

\section{Discussion}

Some consideration are at this point mandatory:

i) The interest in studying the behavior of electronic devices (mainly integrated circuits) in a hostile environment, such as the one of the ATLAS experiment at CERN, is well documented by many papers and technical notes, for example the ATLAS Policy for radiation tolerance [28]. There is a similar interest for the B-field inside the detector. Considering, for example, the New Small Wheel (NSW) upgrade project, the maximum value of B-Field has been simulated. The maximum value of B-field is evaluated as $0.6 \mathrm{~T}$ in proximity of the large sector edge at large radius. It is very interesting to note that uncertainty in B-field evaluation is about $10 \%$ at large value of radius (outer positions), where the estimated value is maximum, whereas it is quite inaccurate at innermost area of the NSW where B-field is only a few hundred Gauss. This allows us to conclude that the B-field will be in any case less than the $1 \mathrm{~T}$ value used as maximum value for the present test. 
ii) It is important to highlight that the efficiency evaluated during the test (83-85\% @2.2 A) is above the typical value given by the manufacturer (about 82\%@2.2 A) reported in Figure 25. This point needs to be further investigated even taking into account the type of instruments used, with particular attention to their uncertainty. However, the efficiency has been calculated using the nominal value of the load $(1.5 \Omega)$. If the wire resistance and the thermal effects on both the load resistor and the wires are considered, a value compatible with the datasheet can be obtained (considering the cable resistance at room temperature equal to $50 \mathrm{~m} \Omega$, as experimentally measured, the efficiency is about 0.82 ). Figure 25 depicts the typical chart of efficiency as given by the manufacturer (figure has been taken by the cited datasheet [25]).

iii)We are interested in evaluating if the device can operate reliably in a hostile environment. Thus, the key indexes are the functionality, simply as ON/OFF answer, and the efficiency as ancillary, even important, features.

iv) In Figure 26 the hysteresis of the efficiency is reported. It is evident that hysteresis is not significant. The small differences that can glimpse between the curve for increasing magnetic field and the curve for decreasing magnetic field are not significant because they are of the same order of magnitude as the resolution of the measuring system adopted for the tests. This means that: a) the device works properly with both increasing and decreasing values of the B-field; $b$ ) temporary and permanent damages are not present up to the experimentally tested B-field values.

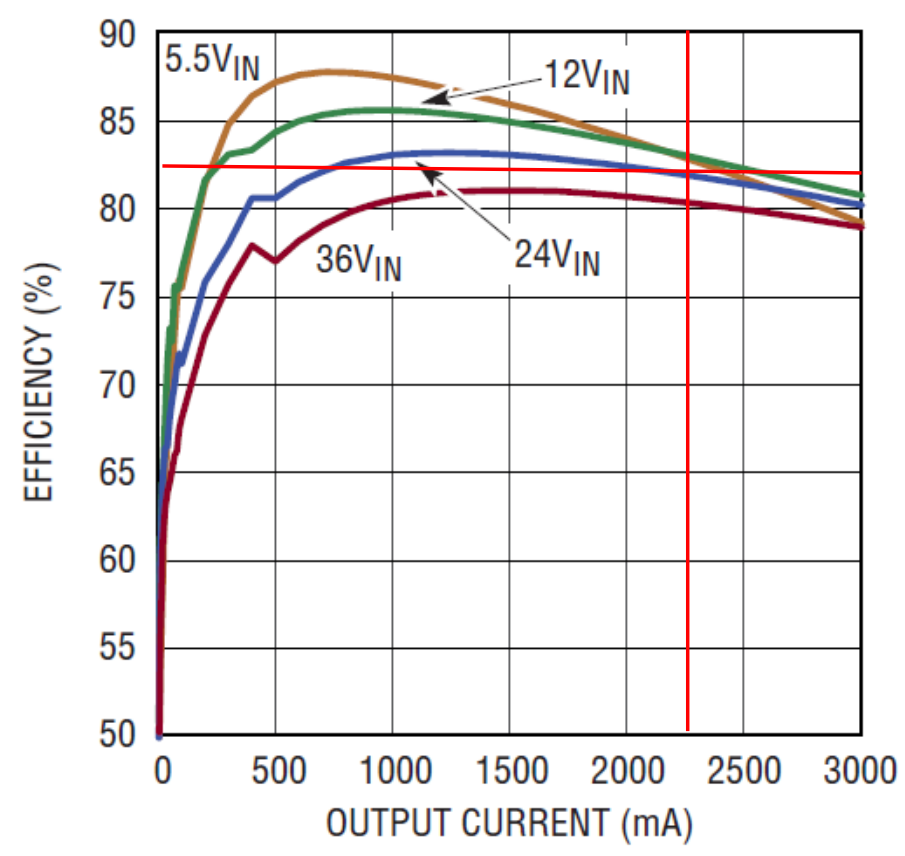

Figure 25 - Typical efficiencies (from LT [25]). 


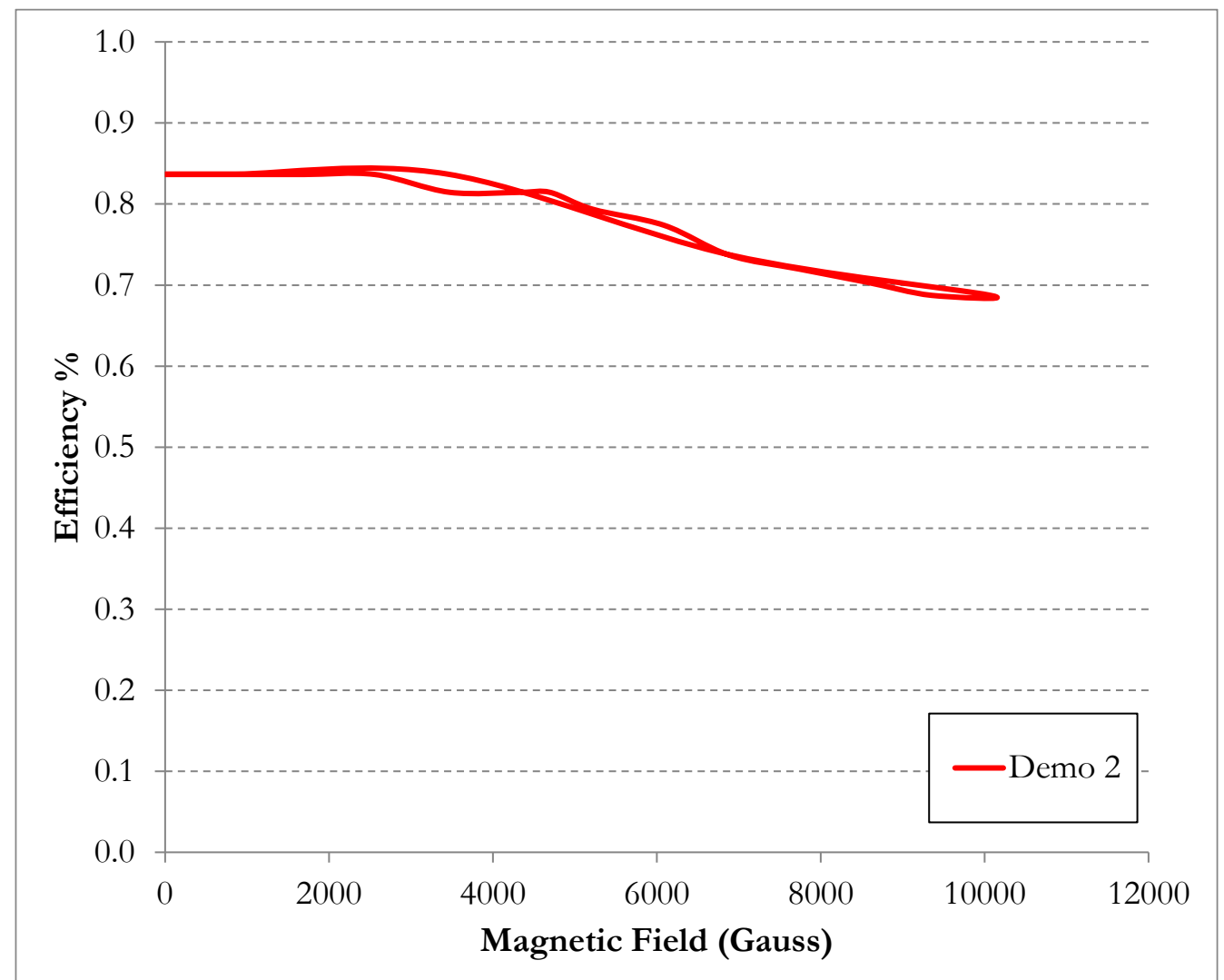

Figure 26 - Measured hysteresis with B-field perpendicular for evaluation board 2. Similar experimental results have been obtained with different B-field orientation.

v) Another consideration concerning the reliability of the considered device can be done [6], [7]. The device is equipped with an output signal referred as PGOOD. This signal can be conveniently used to improve the reliability and, most important, the diagnostics of the system in which the device operates [6], [29], [30] - [35]. The continuous monitoring of the signal is therefore of paramount importance. However, the operation of this signal has not been experimentally investigated in this paper. As previous discussed, we are interested at this point in checking the functionality of the device in terms of Boolean output: fails/not fails. However, the function given by the manufacturer is very interesting and useful in many situations and applications. This function can be used for monitoring purposes, in case the Condition Based Maintenance (CBM) is in operation. It should be noted that a CBM program can be very interesting in this and in other situations. In fact, in order to take into account the necessity of a maintenance activity, two main strategies can be used. In the first type of approach we have the so-called maintenance based on the time, where the maintenance is planned once a year, for example, or we can take into account the operation (e.g. the case of automobiles, where the maintenance is planned taking into account both $\mathrm{km}$ and time). This way to proceed is not able to get the best performance due 
to the fact that the maintenance operation is performed without taking into account the actual situation of the considered system. Different approach is the maintenance based on a well-defined (prior-defined) condition. Here, a monitoring activity is obviously necessary. The signal Pgood can be used at this aim [36]. This approach has been proposed, for example, in [30], [37] - [42]. Consideration about the CBM approach to the maintenance can be found also in [30] and [36] - [42].

vi) Output behavior in terms of noise is also an interesting key point. Concerning the device under test, it is possible to see that the ripple tends to increase along with the magnetic field. The peak-to-peak value of the measured ripple is of about $1.5 \%$, worst case. For example, in the configuration discussed in Section IV.a the ripple tends to increase approximately linearly from 2500 Gauss up, while below this value the ripple is appreciably similar to the one present in the absence of magnetic field.

vii) Two further plots can be useful in order to highlight the general behavior of the devices under test. The following figures reports the way of operation in every tested cases for input current (Figure 27) and for efficiency (Figure 28). In these two figures, $y$-axis are expanded and in both cases, the initial value is different from zero, putting in evidence the variations.

viii) Can be useful to underline that the device here evaluated when operating under magnetic field, together with others, was also extensively tested under photon, neutron and proton radiation. Results are described in [43], [44].

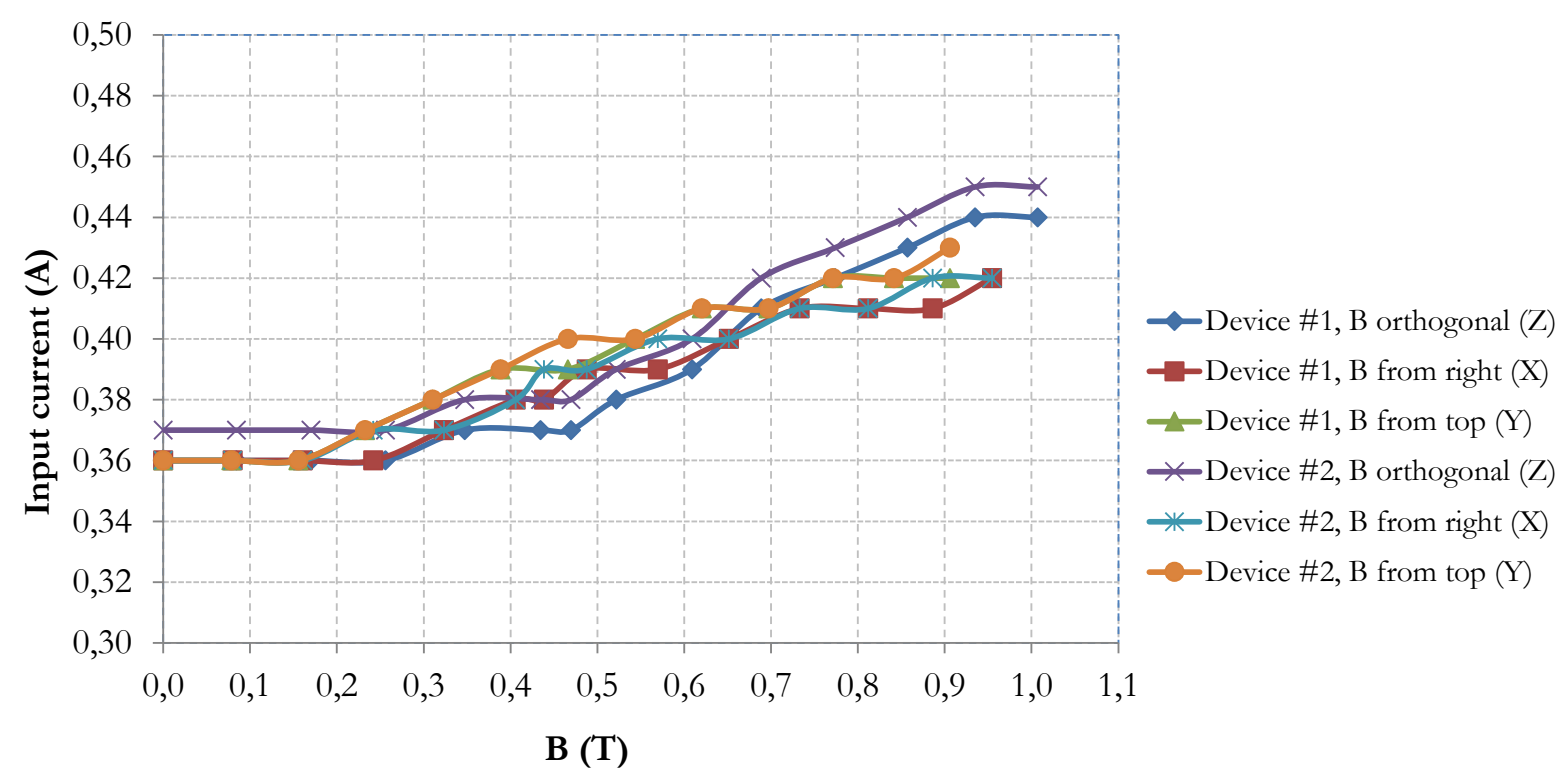

Figure 27 - LTM 8033 - Input current vs B field (for all tested configurations). 


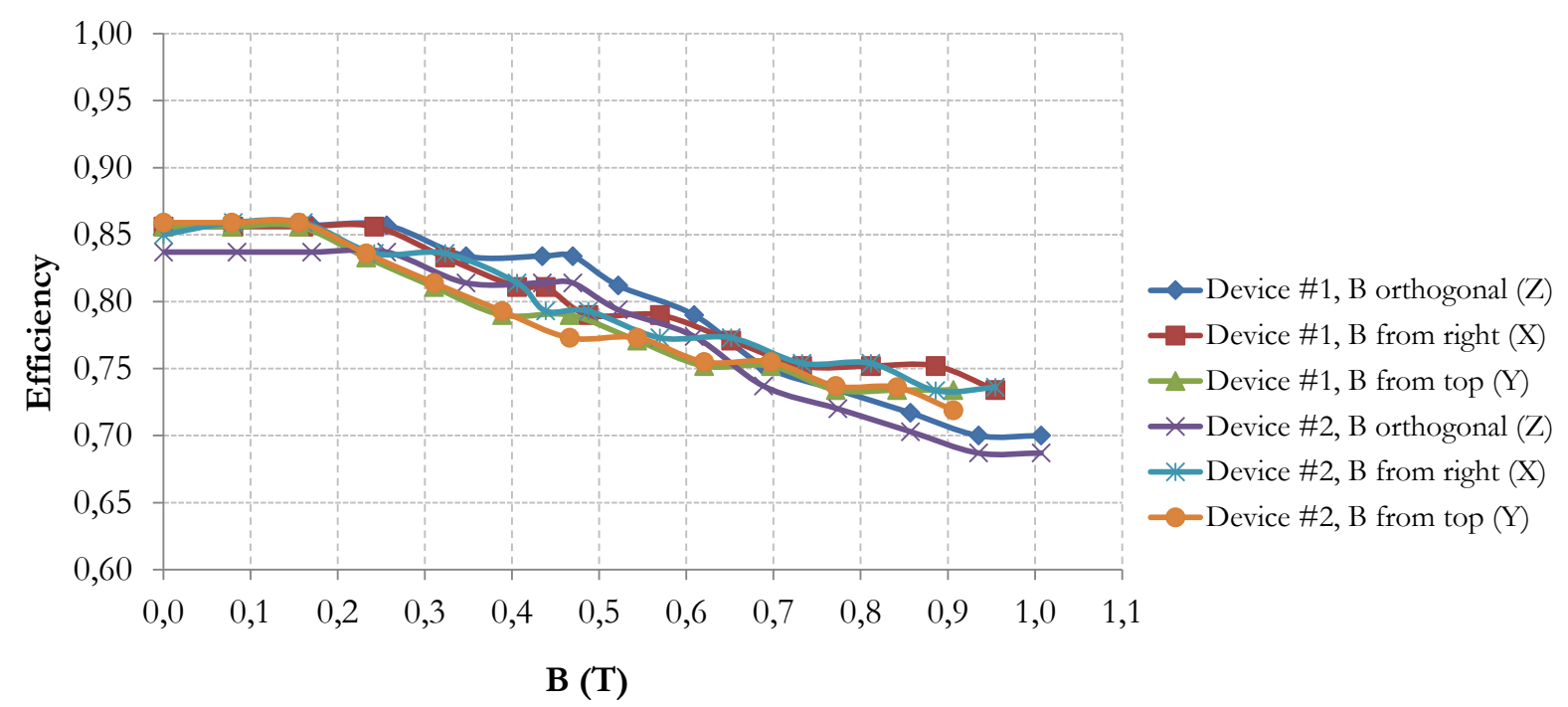

Figure 28 - LTM 8033 - Efficiency vs B field (for all tested configurations).

\section{Conclusions}

In this paper the operation of a commercial DC-DC converter in high B-field has been experimentally evaluated and discussed. After a brief overview about the environment meet in physics experiments and the mandatory specification for devices operation in harsh environment, the experimental activity has been described. In particular, the tested device has been experimentally stressed at high B field up to about 1 Tesla. The experimental setup used for measurements has been described and discussed. The obtained experimental values are completely reported and a deeply discussion has been also given.

Finally, the obtained results allow affirming that, in the specified test conditions, the tested devices work properly up to B-fields, applied in the three directions, of the order of $1 \mathrm{~T}$.

The only evidence of the increasing applied B-field can be seen through a decrease in the efficiency that, however, is still considered tolerable in many applications. Same considerations can be applied to the output ripple.

\section{Acknowledgement}

Authors would like to thank INFN and Università degli Studi di Milano for help during the experimental test at Lasa and for funding research included in this paper. 


\section{References}

[1] http://home.web.cern.ch.

[2] Atlas Collaboration, Observation of a new particle in the search for the Standard Model Higgs boson with the ATLAS detector at the LHC, Physics Letters B, Volume 716, Issue 1, 17 September 2012, Pages 1-29, DOI: 10.1016/j.physletb.2012.08.020, ISSN: 0370-2693, ELSEVIER.

[3] CMS Collaboration, Observation of a new boson at a mass of $125 \mathrm{GeV}$ with the CMS experiment at the LHC, Physics Letters B, Volume 716, Issue 1, 17 September 2012, Pages 30-61, DOI: 10.1016/j.physletb.2012.08.021, ISSN: 0370-2693, ELSEVIER.

[4] G. Aad et al., "The ATLAS experiment at the CERN LHC", Journ. of Instrumentation, vol. 3, S08003, 2008, doi:10.1088/1748-0221/3/08/S08003, ISSN 1748-0221.

[5] P. Cova, N. Delmonte, F. Giuliani, M. Citterio, S. Latorre, M. Lazzaroni, A. Lanza, Thermal optimization of water heat sink for power converters with tight thermal constraints", Microelectronics Reliability, vol. 53, Issues 9-10, September-October 2013, DOI: 10.1016/j.microrel.2013.07.035, ISSN: 0026-2714.

[6] M. Lazzaroni, M. Citterio, S. Latorre, A. Lanza, P. Cova, N. Delmonte, F. Giuliani, POWER SUPPLY SYSTEM FOR THE ATLAS EXPERIMENT: DESIGN SPECIFICATIONS, IMPLEMENTATION, TEST AND FIRST RESULTS, Data di pubblicazione: 2013-10, Pages(s): 5, Publication state: in press, Proceedings of the $14^{\text {th }}$ International Conference on Advanced Technology and Particle Physics (ICATPP 2013), Astroparticle, Particle, Space Physics and Detectors for Physisc Applications Vol. 8, Villa Olmo, Como (Italy), Year: 2013, 23-27 September 2013, Publisher: World Scientific Publisher, ISBN: 978-981-4603-15-7 (hardcover), ISBN: 978-981-4603-17-1 (ebook). pp.: $360-364$.

[7] M. Lazzaroni, L. Cristaldi, L. Peretto, P. Rinaldi and M. Catelani, Reliability engineering: basic concepts and applications in ICT, Springer, ISBN 978-3-642-209826, e-ISBN 978-3-642-20983-3, DOI: 10.1007/978-3-642-20983-3, 2011, SpringerVerlag Berlin Heidelberg.

[8] http://lasa.mi.infn.it/

[9] P. Greenland, Developments in Point of Load Regulation, SEMTECH Corporation 200 Flynn Road, Camarillo, CA 93012, available at internet web page of the company: www.semtech.com/images/promo/developments-in-Point-of-Load-Regulation.pdf. 
[10] M. Alderighi, M. Citterio, M. Riva, S. Latorre, A. Costabeber, A. Paccagnella, F. Sichirollo, G. Spiazzi, M. Stellini, P. Tenti, P. Cova, N. Delmonte, A. Lanza, M. Bernardoni, R. Menozzi, S. Baccaro, F. Iannuzzo, A. Sanseverino, G. Busatto, V. De Luca, F. Velardi, "Power converters for future LHC experiments", Journal of Instrumentation, vol. 7, C03012, 2012. ISSN: 1748-0221. doi: 10.1088/17480221/7/03/C03012.

[11] S. Fiore, C. Abbate, S. Baccaro, G. Busatto, M. Citterio, F. Iannuzzo, A. Lanza, S. Latorre, M. Lazzaroni, A. Sanseverino, F. Velardi, Radiation and magnetic field effects on new semiconductor power devices for HL-LHC experiments, ArXiv, Data di pubblicazione: 2013-10, Pages(s): 5, Publication state: in press, Proceedings of the $14^{\text {th }}$ International Conference on Advanced Technology and Particle Physics (ICATPP 2013), Astroparticle, Particle, Space Physics and Detectors for Physisc Applications Vol. 8, Villa Olmo, Como (Italy), Year: 2013, 23-27 September 2013, Publisher: World Scientific Publisher, URL: http://arxiv.org/abs/1310.1902. ISBN: 978-981-4603-15-7 (hardcover), ISBN: 978-981-4603-17-1 (ebook), pp.: $664-668$.

[12] C. Abbate, M. Alderighi, S. Baccaro, G. Busatto, M. Citterio, P. Cova, N. Delmonte, V. De Luca, S. Gerardin, E. Ghisolfi, F. Giuliani, F. Iannuzzo, A. Lanza, S. Latorre, M. Lazzaroni, A. Paccagnella, M. Riva, A. Sanseverino, G. Spiazzi, F. Velardi "Developments on DC/DC converters for the LHC experiment upgrades", Proc. TWEPP 2013 - Topical Workshop on Electronics for Particle Physics, Perugia (Italy), Sep. 23-27, 2013.

[13] C. Abbate, M. Alderighi, S. Baccaro, G. Busatto, M. Citterio, P. Cova, N. Delmonte, V. De Luca, S. Gerardin, E. Ghisolfi, F. Giuliani, F. Iannuzzo, A. Lanza, S. Latorre, M. Lazzaroni, G. Meneghesso, A. Paccagnella, F. Rampazzo, M. Riva, A. Sanseverino, R. Silvestri, G. Spiazzi, F. Velardi, E. Zanoni, "Radiation performance of new silicon devices for the LHC experiment upgrades", Proc. 11th International Conference on Large Scale Application and Radiation Hardness of Semiconductor Detectors, Florence, Italy, Jul. 3-5, 2013.

[14] M. Lazzaroni, M. Citterio, S. Latorre, A. Lanza, P. Cova, N. Delmonte, F. Giuliani, "Ottimizzazione termica di dissipatori per convertitori di potenza per applicazioni in ambienti ostili", Atti del XXX Congresso Nazionale Associazione "Gruppo Misure Elettriche ed Elettroniche" (GMEE 2013), pp. 123-124, Trento (Italy), Sep. 8-11, 2013. ISBN: 978-88-8443-496-8. 
[15] C. Abbate, M. Alderighi, S. Baccaro, G. Busatto, M. Citterio, P. Cova, N. Delmonte, V. De Luca, S. Fiore, S. Gerardin, E. Ghisolfik, F. Giuliani, F. Iannuzzo, A. Lanza, S. Latorre, M. Lazzaroni, G. Meneghesso, A. Paccagnella, F. Rampazzo, M. Riva, A. Sanseverino, R. Silvestri,G. Spiazzi, F. Velardi, E. Zanoni, Radiation performance of new semiconductor power devices for the LHC experiment upgrades, 11th International Conference on Large Scale Applications and Radiation Hardness of Semiconductor Detectors, July 3-5, 2013 Florence, Italy, PoS: Proceedings of Science, ISSN 18248039.

[16] C. Abbate, M. Alderighi, S. Baccaro, G. Busatto, M. Citterio, P. Cova, N. Delmonte, V. De Luca, S. Fiore, S. Gerardin, E. Ghisolfi, F. Giuliani, F. Iannuzzo, A. Lanza, S. Latorre, M. Lazzaroni, G. Meneghesso, A. Paccagnella, F. Rampazzo, M. Riva, A. Sanseverino, R. Silvestri, G. Spiazzi, F. Velardi, E. Zanoni, Developments on DC/DC converters for the LHC experiment upgrades, Journal of Instrumentation, Volume 9, Issue 2, February 2014, JINST 9 C02017, doi:10.1088/1748-0221/9/02/C02017, link: http://iopscience.iop.org/1748-0221/9/02/C02017/, ISSN: 1748-0221.

[17] C. Abbate, S. Baccaro, G. Busatto, M. Citterio, P. Cova, N. Delmonte, V. De Luca, S. Fiore, F. Giuliani, F. Iannuzzo, A. Lanza, S. Latorre, M. Lazzaroni, A. Sanseverino, G. Spiazzi, F. Velardi: "Testing Integrated COTS DC/DC Converters in Hostile Environment", presented at the 4th Common ATLAS CMS Electronics Workshop for LHC Upgrades (ACES 2014), CERN (Switzerland), March 18 - 20, 2014.

[18] Lazzaroni, M. ; Citterio, M. ; Latorre, S. ; Lanza, A. ; Spiazzi, G., Point of Load for LHC experiments: Testing the behaviour in hostile environment, Proceedings of the 2014 IEEE International Instrumentation and Measurement Technology Conference (I2MTC), May 12-15, 2014, Radisson Montevideo Victoria Plaza Hotel \& Conference Center, Montevideo, Uruguay, DOI: 10.1109/I2MTC.2014.6860829, Publication Year: 2014 , Page(s): 681 - 686, INSPEC Accession Number: 14467626, ISBN: 978-1-46736385-3, ISSN: 1091-5281, Scopus ID 2-s2.0-84905674455, WOS: 14467626, Publisher: IEEE, Piscataway, NJ, USA.

[19] Lazzaroni, M. ; Citterio, M. ; Latorre, S. ; Lanza, A. ; Cova, P. ; Delmonte, N. ; Giuliani, F., Metrological characterization of a cold plate test bench, Proceedings of the 2014 IEEE International Instrumentation and Measurement Technology Conference (I2MTC), May 12-15, 2014, Radisson Montevideo Victoria Plaza Hotel \& Conference Center, Montevideo, Uruguay, DOI: 10.1109/I2MTC.2014.6860773, Publication Year: 2014 , Page(s): 386 - 391, INSPEC Accession Number: 14467589, ISBN: 978-1-4673- 
6385-3, ISSN: 1091-5281, Scopus ID s2.0-84905675173, WOS: 14467589, Publisher: IEEE, Piscataway, NJ, USA.

[20] Lazzaroni, M. ; Citterio, M. ; Latorre, S. ; Lanza, A. ; Cova, P. ; Delmonte, N. ; Giuliani, F., A main converter for future LHC experiments: Features measurement and reliability considerations, Proceedings of the 2014 IEEE International Instrumentation and Measurement Technology Conference (I2MTC), May 12-15, 2014, Radisson Montevideo Victoria Plaza Hotel \& Conference Center, Montevideo, Uruguay, DOI: 10.1109/I2MTC.2014.6860884, Publication Year: 2014 , Page(s): 954 - 959, INSPEC Accession Number: 14467376, ISBN: 978-1-4673-6385-3, ISSN: 1091-5281, Scopus ID 2-s2.0-84905694070, WOS: 14467376, Publisher: IEEE, Piscataway, NJ, USA.

[21] M. Lazzaroni, M. Citterio, S. Latorre, A. Lanza, G. Spiazzi, MISURE SU PoL PER APPLICAZIONI IN AMBIENTE OSTILE, Atti del XXXI Congresso Nazionale dell'Associazione GRUPPO MISURE ELETTRICHE ED ELETTRONICHE, GMEE 2014, Ancona, 11-13 september 2014, pp: 109-110, 2014, Universitas Studiorum S.r.1. Casa Editrice, via Sottoriva, 9 - 46100 Mantova (MN), ISBN: 978-88-97683-66-7, ISBN: 978-88-97683-67-4 (e-book), Set. 2014.

[22] M. Lazzaroni, M. Citterio, S. Latorre, A. Lanza, P. Cova, N. Delmonte, F. Giuliani, CARATTERIZZAZIONE METROLOGICA DI UN BANCO DI PROVA PER DISSIPATORI, Atti del XXXI Congresso Nazionale dell'Associazione GRUPPO MISURE ELETTRICHE ED ELETTRONICHE, GMEE 2014, Ancona, 11-13 settembre 2014, pp: 111-112, 2014, Universitas Studiorum S.r.l. - Casa Editrice, via Sottoriva, 9 - 46100 Mantova (MN), ISBN: 978-88-97683-66-7, ISBN: 978-88-9768367-4 (e-book), Set. 2014.

[23] M. Lazzaroni, M. Citterio, S. Latorre, A. Lanza, P. Cova, N. Delmonte, F. Giuliani, CARATTERIZZAZIONE DI UN ALIMENTATORE PER LHC, Atti del XXXI Congresso Nazionale dell'Associazione GRUPPO MISURE ELETTRICHE ED ELETTRONICHE, GMEE 2014, Ancona, 11-13 settembre 2014, pp: 113-114, 2014, Universitas Studiorum S.r.l. - Casa Editrice, via Sottoriva, 9 - 46100 Mantova (MN), ISBN: 978-88-97683-66-7, ISBN: 978-88-97683-67-4 (e-book), Set. 2014.

[24] M. Lazzaroni, M. Citterio, S. Latorre, A. Lanza, G. Spiazzi, SVILUPPO DI DC-DC CONVERTER PER APPLICAZIONI IN AMBIENTE OSTILE, Atti del XXXI Congresso Nazionale dell'Associazione GRUPPO MISURE ELETTRICHE ED ELETTRONICHE, GMEE 2014, Ancona, 11-13 settembre 2014, pp: 117-118, 2014, 
Universitas Studiorum S.r.l. - Casa Editrice, via Sottoriva, 9 - 46100 Mantova (MN), ISBN: 978-88-97683-66-7, ISBN: 978-88-97683-67-4 (e-book), Set. 2014.

[25] LTM8033 Datasheet, Linear Technology, available on line: www.linear.com.

[26] LTM8033: 36VIN, 3A Low EMI Step-Down $\mu$ Module Regulator, Demo-board manual, Linear Technology, available on line: $\underline{w w w . l i n e a r . c o m}$.

[27] ISO/IEC 99:2007-12, International vocabulary of metrology - Basic and general concepts and associated terms (VIM), 3rd edition.

[28] ATLAS Policy on Radiation Tolerant Electronics, ATLAS Project Document. No ATCTE-QA-0001, 21 July 2000.

[29] P. Cova, N. Delmonte, F. Giuliani, M. Citterio, S. La Torre, A. Lanza, M. Lazzaroni, "Thermal modeling and characterization of power converters for LHC power supplies", Proc. 12th IMEKO TC10 Workshop on Technical Diagnostics - New Perspectives in Measurements, Tools and Techniques for Industrial Applications, pp. 202-207, Firenze (Italy), Jun. 6-7, 2013. ISBN: 978-88-903149-8-8.

[30] L. Cristaldi, M. Faifer, M. Rossi, S. Toscani, M. Lazzaroni, "Condition based maintenance through electrical signature analysis: a case study", Instrumentation and Measurement Technology Conference (I²MTC), Page(s): 1169 - 1174, 2010, ISBN: 978-1-4244-2833-5, DOI: 10.1109/IMTC.2010.5488021, ISSN: 1091-5281.

[31] L. Cristaldi, M. Faifer, M. Lazzaroni, S. Toscani, “An inverter-fed induction motor diagnostic tool based on time-domain current analysis", IEEE Trans. on Instrumentation and Measurement, vol. 58, Issue 5, pp. 1454 - 1461, May 2009, DOI: 10.1109/TIM.2009.2012958, ISSN: 0018-9456.

[32] L. Cristaldi, M. Lazzaroni, A. Monti, F. Ponci, F.E. Zocchi, A genetic algorithm for fault identification in electrical drives: A comparison with neuro-fuzzy computation, Proceedings of the 21st IEEE Instrumentation and Measurement Technology Conference, Como, Italy, 18 - 20 May 2004, ISSN: 1091-5281, ISBN: 0-7803-8248-X, Volume 2, 2004, Pages 1454-1459, DOI: 10.1109/IMTC.2004.1351341.

[33] A. Azzini, L. Cristaldi, M. Lazzaroni, A. Monti, F. Ponci, A.G.B. Tettamanzi, Incipient fault diagnosis in electrical drives by tuned neural networks, Proceedings of the IEEE Instrumentation and Measurement Technology Conference, Hilton Sorrento Palace, Sorrento, Italy, 24-27 April 2006, ISSN: 1091-5281, ISBN: 0-7803-9360-0, Pages 1284-1289, DOI: 10.1109/IMTC.2006.328495.

[34] G. D’Antona, E. Carminati, M. Lazzaroni, R. Ottoboni, C. Svelto “AC Current Measurements Via Digital Processing of Rogowski Coils Signal”, IEEE Instrumentation 
and Measurement Technology Conference - Anchorage, AK, USA, 21-23 May 2002 Pagg. 693 - 698, DOI: 10.1109/IMTC.2002.1006926, ISBN: 0-7803-7218-2, ISSN: 1091-5281.

[35] R. Faranda, M. Lazzaroni, Industrial low cost temperature measurement in permanent electro-magnetic platens, DOI: 10.1016/j.measurement.2012.07.004, URL: http://www.sciencedirect.com/science/article/pii/S0263224112002734, Measurement, ISSN: 0263-2241, Volume 46, Issue 1, January 2013, Pages 324-335. Scopus: s2.084870253834. WOS: 000313155700034.

[36] M. Catelani, L. Ciani, L. Cristaldi, M. Faifer, M. Lazzaroni, Electrical performances optimization of Photovoltaic Modules with FMECA approach, Measurement 46 (2013), Pages 3898-3909, DOI: 10.1016/j.measurement.2013.08.003, ISSN: 0263-2241, Sopus ID: 2-s2.0-84883522357.

[37] M. Lazzaroni, S. Ferrari, L. Cristaldi, M.A. Annoni, Tool for Working Condition and Nozzles Classification for Water Jet Systems, in: Instrumentation and Measurement Technology Conference Proceedings, IMTC 2008. IEEE, Digital Object Identifier: 10.1109/IMTC.2008.4547268, 2008, pp. 1435-1440.

[38] L. Cristaldi, M. Faifer, S. Toscani, M. Lazzaroni, An on-board device for condition based maintenance on inverted fed induction machines, in: Instrumentation and Measurement Technology Conference, I2MTC '09. IEEE, Digital Object Identifier: 10.1109/IMTC.2009.5168633, 2009, pp. 1177-1182.

[39] L. Cristaldi, M. Faifer, M. Rossi, L. Ciani, M. Lazzaroni, S. Toscani, Photovoltaic plant efficiency evaluation: a proposal, in: Proc. of $12^{\text {th }}$ IMEKO TC10 Workshop on Technical Diagnostics, Florence, Italy, June 2013, pp. 260-265.

[40] Cristaldi L., Faifer M., Lazzaroni M., Khalil A.F. M. M., Catelani M., Ciani L., Failure Modes Analysis and Diagnostic Architecture for Photovoltaic Plants, Proccedings of the 13 th IMEKO TC10 Workshop on Technical Diagnostics Advanced measurement tools in technical diagnostics for systems' reliability and safety, June 26-27, 2014, Warsaw, Poland, ISBN: 978-1-63266-984-1, pagg(s): 206-211.

[41] M. Catelani, L. Ciani, L. Cristaldi, M. Faifer, M. Lazzaroni, M. Rossi, Characterization of photovoltaic panels: the effects of dust, in: Proc. Of 2nd IEEE ENERGYCON Conference \& Exhibition, 2012/Advances in Energy Conversion Symposium, September 2012, Florence (Italy), pp. 49-54, doi: 10.1109/EnergyCon.2012.6348198.

[42] M. Catelani, L. Ciani, L. Cristaldi, M. Faifer, M. Lazzaroni, P. Rinaldi, “FMECA Technique on Photovoltaic Module', in: Proc. Of IEEE - International Instrumentation 
And Measurement Technology Conference (I2MTC) - Binjiang, Hangzhou, China, May 2011, pp. 1717-1722.

[43] S. Fiore, J. Ameel, D. Amidei, S. Baccaro, M. Citterio, R. Edgar, A. Lanza, S. Latorre, M. Lazzaroni, K. Sekhon, "Radiation and Magnetic Field Effects on Commercial DCDC Converters for HL-LHC Experiments”, accepted for IEEE NSS 2014.

[44] R. Edgar, J. Ameel, K. Sekhon, D. Amidei, A. Lanz, S. Baccaro, M. Citterio, S. Fiore, M. Lazzaroni, P. Cova, N. Delmonte, S. Latorre, "Radiation-Hard Power Electronics for the ATLAS New Small Wheel", accepted at TWEPP 2014 (Topical Workshop on Electronics for Particle Physics). 